Check for updates

Cite this: Mater. Adv., 2021,

2, 1570

Received 30th November 2020

Accepted 27th January 2021

DOI: 10.1039/d0ma00938e

rsc.li/materials-advances

\title{
Applications of $\mathrm{MXene}\left(\mathrm{Ti}_{3} \mathrm{C}_{2} \mathrm{~T}_{x}\right)$ in photocatalysis: a review
}

\author{
Xing Li, (D) ${ }^{a}$ Yang Bai, ${ }^{a}$ Xian Shi, ${ }^{b}$ Na Su, ${ }^{a}$ Gongzhe Nie, ${ }^{a}$ Rumeng Zhang, ${ }^{c}$ \\ Hongbo $\mathrm{Nie}^{\text {ad }}$ and Liqun $\mathrm{Ye}$ (D)*ae
}

\begin{abstract}
MXenes are two-dimensional nanomaterials, which can be constructed from different elements. The rich interlayer groups, surface groups, and the flexible layer spacing of MXenes make them ideal catalysts. Among these, $\mathrm{Ti}_{3} \mathrm{C}_{2} \mathrm{~T}_{x}$ has gained particular attention as a photocatalyst for photocatalytic $\mathrm{CO}_{2}$ reduction reactions $\left(\mathrm{CO}_{2} \mathrm{RR}\right)$, hydrogen evolution reactions (HER), and photocatalytic degradation reactions. The structure of $\mathrm{Ti}_{3} \mathrm{C}_{2} \mathrm{~T}_{x}$, hydrophilic surface functional groups, and the Gibbs free energy for hydrogen adsorption lead to the excellent photocatalytic HER performance of this material. Numerous surface defects on $\mathrm{Ti}_{3} \mathrm{C}_{2} \mathrm{~T}_{x}$ also provide plentiful $\mathrm{CO}_{2}$ adsorption sites for $\mathrm{CO}_{2} \mathrm{RR}$. It is the structure of two-dimensional nanomaterials and their high-speed electron transport channels that enable their excellent catalytic oxidation activity. However, at present, there are still challenges that limit their further application, the most significant of which is the material stability. In order to overcome this, the synthetic routes to prepare these photocatalysts need to be adapted.
\end{abstract}

\section{Introduction}

Photocatalysis is an environment-friendly technology developed in the 20th century. When light is absorbed by some special semiconductors, namely "photocatalysts", electrons $\left(\mathrm{e}^{-}\right)$originally in the valence band (VB) are excited to the conduction band (CB) and holes $\left(\mathrm{h}^{+}\right)$are formed in the initial position. Free electrons with strong reducibility can reduce the valence state of some elements in compounds (such as carbon in $\mathrm{CO}_{2}$ and nitrogen in $\mathrm{N}_{2}$ ) when regular methods are not useful or cost too much. Thus far, photocatalysis has shown its huge application prospects in clean energy, environmental remediation, and many other fields; currently, researchers are heading towards new photocatalyst development and reaction mechanisms. Photocatalytic hydrogen evolution reaction (HER), $\mathrm{CO}_{2}$ reduction reaction $\left(\mathrm{CO}_{2} \mathrm{RR}\right)$, and photocatalytic degradation reaction represent the three main aspects of photocatalysis.

\footnotetext{
${ }^{a}$ State Key Laboratory of Oil and Gas Reservoir Geology and Exploitation, School of Oil \& Natural Gas Engineering, Southwest Petroleum University, Chengdu, 610500, China. E-mail: baiyanghyq@foxmail.com

${ }^{b}$ Institute of Fundamental and Frontier Sciences, University of Electronic Science and Technology of China, Chengdu, 610054, China

${ }^{c}$ Key Laboratory of Ecological Security for Water Source Region of Mid-line Project of South-to-North Water Diversion of Henan Province, College of Chemistry and Pharmaceutical Engineering, Nanyang Normal University, Nanyang, 473061, China

${ }^{d}$ CNOOC (China) Co., LTD. Tianjing Branch, Tianjing, 300452, China

${ }^{e}$ College of Materials and Chemical Engineering, Key Laboratory of Inorganic Nonmetallic Crystalline and Energy Conversion Materials, China Three Gorges University, Yichang, 443002, China. E-mail: lqye@ctgu.edu.cn
}

Photocatalytic nanomaterials have an extensive number of potential applications. When their particle size is below a certain value, the Fermi level of the electronic energy levels morphs from continuous to discrete levels and the energy gap grows wider. These semiconductors are, therefore, more susceptible to photon excitation, which improves their photocatalytic activity. ${ }^{1}$

Nanomaterials can be divided into four categories, according to the dimensions of their structural scale: (1) zero-dimensional materials, e.g., groups of nanostructure clusters; (2) onedimensional nanomaterials, e.g., fibrous nanotubes, nanowires, nanoribbons, or other related structures; (3) two-dimensional nanomaterials, e.g., layered nanomaterials, quantum wells, superlattices, and other structures; (4) three-dimensional nanomaterials, e.g., composite structures consisting of one or more zero-dimensional, one-dimensional, or two-dimensional nanomaterials. The first three are collectively known as low Vannami materials. In low Vannami materials, two-dimensional nanomaterials show significant changes in the surface, electron energy levels, state density, and other aspects compared with three-dimensional materials. This due to the fact that their thickness is greatly reduced compared to other two-dimensional materials; thus, these possess unique optical and electronic characteristics, which make them a hot topic in catalysis. ${ }^{2,3}$

MXenes are two-dimensional nanomaterials and have a general material formula of $\mathrm{M}_{n+1} \mathrm{X}_{n} \mathrm{~T}_{x}$. In this formula, $\mathrm{M}$ represents nitrogen or carbon, $\mathrm{X}$ is generally a transition metal element, and $\mathrm{T}$ represents the functional groups. MXenes typically consist of transition metal carbides, nitrides, or carbides that are several 
atomic layers thick. It was first reported in $2011^{4}$ that MXene materials have comparable conductivity towards transition metal carbides due to the presence of hydroxy groups or terminal oxygen species on their surfaces. The most important feature of this range of materials is that, unlike conventional battery materials, they provide more channels for ions to move through, thus dramatically increasing their speed.

$\mathrm{Ti}_{3} \mathrm{C}_{2} \mathrm{~T}_{x}$ was the first discovered MXene material and is also the most widely used MXene material in the field of photocatalysis. ${ }^{5-7}$ It was first obtained by etching the $\mathrm{Al}$ layer of $\mathrm{Ti}_{3} \mathrm{AlC}_{2}$ with hydrofluoric acid. In this paper, the application of $\mathrm{Ti}_{3} \mathrm{C}_{2} \mathrm{~T}_{x}$ as a photocatalyst and approaches to improve its catalytic performance are summarized.

\section{MXene}

2.1 From MAX to MXene. MXenes are a type of twodimensional nanomaterials with covalent bonds formed between the early transition elements and nitrogen or carbon elements. This furnishes an intramolecular skeleton in which the layers are connected by hydrogen bonds. Since the first Mxene, $\mathrm{Ti}_{3} \mathrm{C}_{2} \mathrm{~T}_{x}$, was discovered in 2011, more than 20 kinds of MXene materials including $\mathrm{M}_{2} \mathrm{X}, \mathrm{M}_{3} \mathrm{X}_{2}$, and $\mathrm{M}_{4} \mathrm{X}_{3}$ have been successively prepared. ${ }^{7,8}$ Due to their unique structure and properties, MXenes have been widely favored for use in battery applications.

The preparation of MXenes can be divided into two approaches, namely, bottom-up and top-down. Presently, the top-down etching method is commonly employed. This is due to the MAX phase ${ }^{9,10}$ (commonly, M means early transition metal elements such as $\mathrm{Ti}$ and $\mathrm{Nb}$; $\mathrm{A}$ represents the $\mathrm{Al}$ or $\mathrm{Si}$ layer; $\mathrm{X}$ represents $\mathrm{C}$ or $\mathrm{N}$ elements) as $\mathrm{M}$ is mainly composed of metallic bonds between the atoms, which are connected to $\mathrm{A}$. The chemical properties are largely dictated by A. By using certain concentrations of hydrofluoric acid or $\mathrm{LiF} / \mathrm{HCl}^{11}$ to etch the MAX phase of $\mathrm{Ti}_{3} \mathrm{AlC}_{2}$, ternary carbides within the titanium carbon layers become closer to each other. In this process, the $\mathrm{Al}$ layer is etched away gradually, resulting in a greater carbontitanium interlayer spacing in the $\mathrm{Ti}_{3} \mathrm{C}_{2} \mathrm{~T}_{x}$ product. In order to obtain $\mathrm{Ti}_{3} \mathrm{AlC}_{2}$ with a graphene-like structure consisting of only a few or single layers, mechanical or chemical intercalation dissection is required. However, when chemical intercalation is used for stripping, some organic molecules may occupy the active sites exposed on the surface, which is unfavorable for photocatalytic reactions.

Etching is a slow process, as shown in Fig. 1(a). In this process, Al layers are gradually peeled off, while the $\mathrm{Ti}-\mathrm{C}$ skeleton layers are not damaged because of their strong ionic bonding. ${ }^{12}$ Free groups such as $-\mathrm{OH}$ and some $\mathrm{H}_{2} \mathrm{O}$ molecules enter into the framework of $\mathrm{Ti}-\mathrm{C}$ and become inter-connected by hydrogen bonds, which expands the layer spacing of $\mathrm{Ti}_{3} \mathrm{C}_{2} \mathrm{~T}_{x}$. This permits ions with a large radius to enter the layer spacing, ${ }^{13}$ providing an operating space for the ion intercalation method to peel-off few layers of $\mathrm{Ti}_{3} \mathrm{C}_{2} \mathrm{~T}_{x}$. The number of $-\mathrm{OH}$ groups and $\mathrm{H}_{2} \mathrm{O}$ molecules within the interlayer space accounts for the large electrical capacity of $\mathrm{Ti}_{3} \mathrm{C}_{2} \mathrm{~T}_{x}$.

$\mathrm{Ti}_{3} \mathrm{C}_{2} \mathrm{~T}_{x}$ obtained by direct etching with hydrofluoric acid possesses a different morphology to $\mathrm{Ti}_{3} \mathrm{C}_{2} \mathrm{~T}_{x}$ obtained by etching with $\mathrm{LiF} / \mathrm{HCl}$. Furthermore, NMR spectroscopy revealed a greater number of $-\mathrm{OH}$ and $-\mathrm{F}$ functional groups on the surface of $\mathrm{Ti}_{3} \mathrm{C}_{2} \mathrm{~T}_{x}$ etched by hydrofluoric acid, while $\mathrm{LiF} / \mathrm{HCl}$ etching furnished a material with predominantly $-\mathrm{O}$ functional groups.

\subsection{Structure and properties of $\mathrm{Ti}_{3} \mathrm{C}_{2} \mathrm{~T}_{x}$}

2.2.1 Structure of $\mathbf{T i}_{3} \mathbf{C}_{2} \mathbf{T}_{\boldsymbol{x}}$. As shown in Fig. 2(a), the structure of $\mathrm{Ti}_{3} \mathrm{C}_{2} \mathrm{~T}_{x}$ is comprised of three parts: the intralayer skeleton region, the interlayer region, and the surface terminating groups. In the intramolecular skeleton region, $\mathrm{Ti}$ atoms and $\mathrm{C}$ atoms are stacked alternately to form ionic bonds, and the skeleton of the entire main structure is formed on this basis. In the interlayer region, it was found through neutron diffraction that the interaction between the layers is established through hydrogen bonding between either $\mathrm{O}$ or $\mathrm{F}$ atoms on the surface and van der Waals forces between these atoms. The strength of interlayer hydrogen bonding depends not only on the orientation of $-\mathrm{OH}$ relative to the entire sheet but also on the number and distribution of the $-\mathrm{OH}$ groups. When there is water between the layers, it can also participate in hydrogen bonding. In addition, a large number of terminal groups are

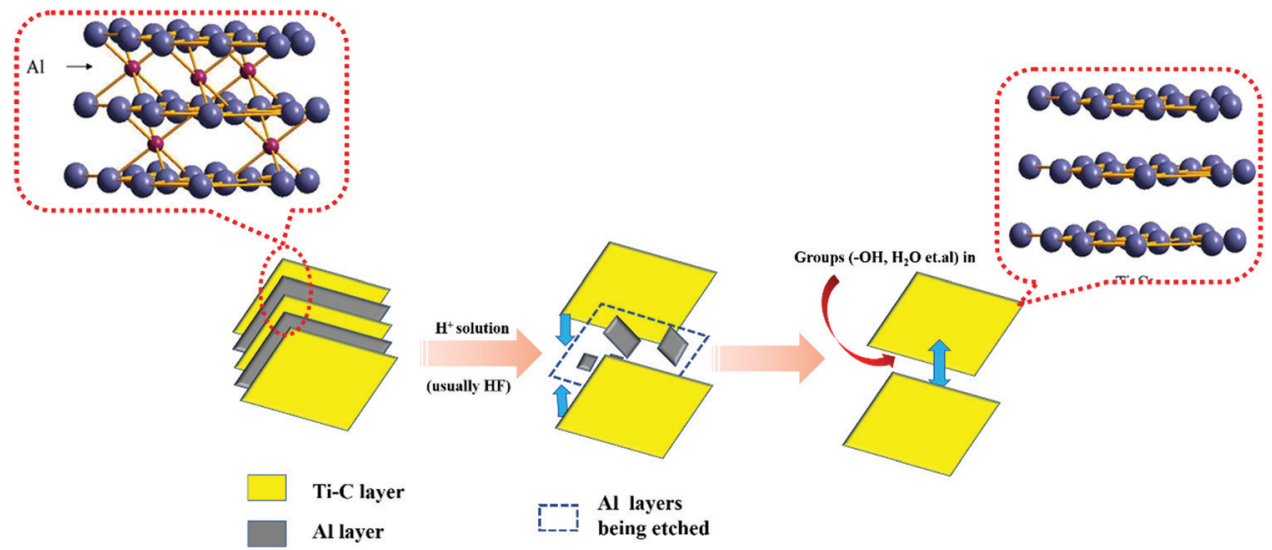

Fig. 1 The process of etching $\mathrm{Ti}_{3} \mathrm{AlC}_{2}$ to yield $\mathrm{Ti}_{3} \mathrm{C}_{2}$. 
(a)
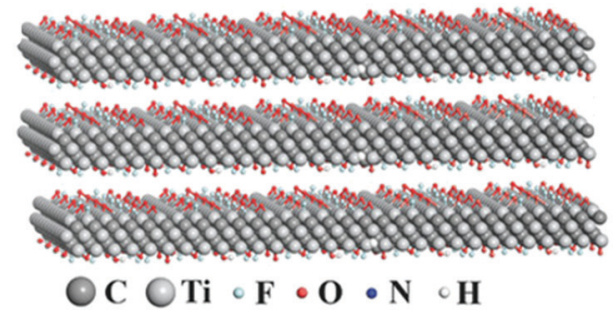

(b)

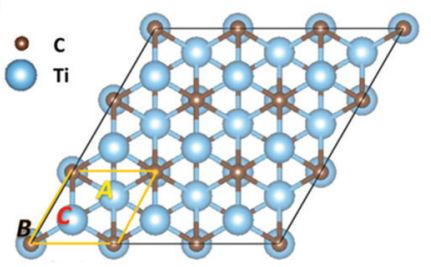

(c)

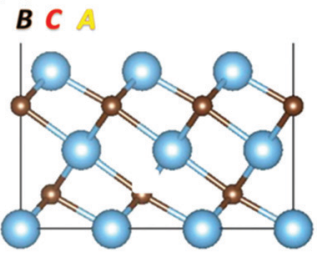

Fig. 2 Schematic diagram showing the crystal structure of $\mathrm{Ti}_{3} \mathrm{C}_{2}(\mathrm{a})^{19}$ and its monolayer with (b) top and (c) side view. The large blue balls represent $\mathrm{Ti}$ atoms and the small brown balls represent $C$ atoms. The highlighted unit cell indicates the high symmetry $\mathrm{A}, \mathrm{B}$, and $\mathrm{C}$ adatom sites. ${ }^{20}$

randomly distributed on the surface of the $\mathrm{Ti}_{3} \mathrm{C}_{2} \mathrm{~T}_{x}$ main structure. These surface groups are directly bonded to the exposed surface and $\mathrm{Ti}_{3} \mathrm{C}_{2} \mathrm{~T}_{x}$ is obtained by top-down etching, which mainly includes surface groups such as $-\mathrm{O},-\mathrm{OH}$, and $-\mathrm{F}$. After a period of placement, the $-\mathrm{F}$ groups can be replaced by -O groups. The surface groups have a great influence on the properties of the $\mathrm{Ti}_{3} \mathrm{C}_{2} \mathrm{~T}_{x}$ formed, which can be analyzed by electron energy loss spectroscopy (TEM), ${ }^{14,15}$ neutron scattering, ${ }^{16}$ and NMR techniques. ${ }^{17,18}$ These experiments confirm that the surface functional groups of $\mathrm{Ti}_{3} \mathrm{C}_{2} \mathrm{~T}_{x}$ are randomly distributed with $-\mathrm{O},-\mathrm{OH}$, and $-\mathrm{F}$ all directly bonded to the surface of the exposed MXene plane. Furthermore, there are no adjacent $-\mathrm{OH}$ functional groups found between the layers. The presence of cations between the layers causes the MXene lamellae to slide easily relative to each other, changing their rheological properties and resulting in their clay-like properties.

2.2.2 Properties of $\mathrm{Ti}_{3} \mathrm{C}_{2} \mathrm{~T}_{\boldsymbol{x}}$. The structure of $\mathrm{Ti}_{3} \mathrm{C}_{2} \mathrm{~T}_{x}$ determines the electric storage performance. $\mathrm{As} \mathrm{Ti}_{3} \mathrm{C}_{2} \mathrm{~T}_{x}$ has a wide spacing between the layers, the ions can travel through the layers at a high speed, whilst the hydroxyl or terminal oxygen groups on the surface furnish a material with excellent conductivity. Both factors are important for the use of these MXene materials in batteries. ${ }^{20-25}$

Various surface groups (such as $-\mathrm{O},-\mathrm{F}$, and $-\mathrm{OH}$ ) have supplied abundant anchored sites for the base photocatalyst to form efficient heterojunction structures, which are ideal for photocatalytic activities. ${ }^{26}$ There is also a large number of exposed metal sites on the surface, which can be used as active sites for reactions.

The surface chemical state of MXene materials has a large influence on the regulation of its physical properties. When $-\mathrm{F}$ on the surface is replaced by an -O group, the electrochemical performance is improved. For example, when $\mathrm{Ti}_{3} \mathrm{C}_{2} \mathrm{~T}_{x}$ is treated with a $\mathrm{KOH}$ and $\mathrm{CH}_{3} \mathrm{OOK}$ solution, the $-\mathrm{O}$ groups on the surface increase, along with the electric capacity. Under an

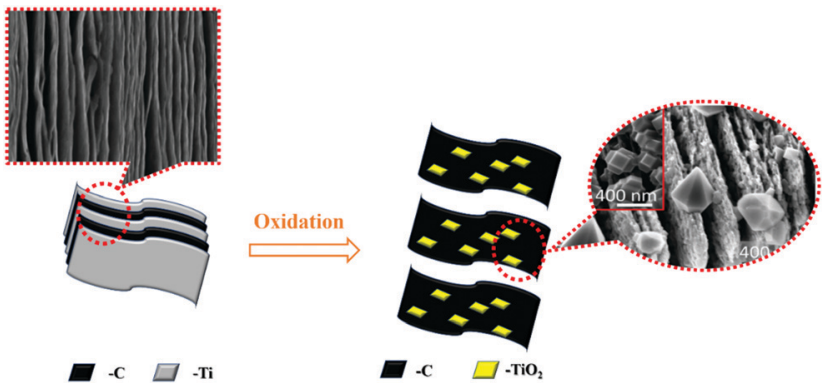

Fig. 3 Oxidation process of $\mathrm{Ti}_{3} \mathrm{C}_{2} \mathrm{~T}_{x}$

atmosphere of $\mathrm{N}_{2}$, Ar, or other inert gases, the number of $-\mathrm{F}$ groups on the surface of $\mathrm{Ti}_{3} \mathrm{C}_{2} \mathrm{~T}_{x}$ is reduced, after which the electrical capacity is greatly increased.

$\mathrm{Ti}_{3} \mathrm{C}_{2} \mathrm{~T}_{x}$ shows an excellent absorption of light between $300 \mathrm{~nm}$ and $500 \mathrm{~nm} .{ }^{27}$ Recently, researchers have even found that the absorption can be broadened to the near-infrared (NIR) region. According to a further study, this may be related to its surface plasmon resonance (SPR), and the thinner the material, the stronger the SPR. ${ }^{28}$ Such a peculiarity makes $\mathrm{Ti}_{3} \mathrm{C}_{2} \mathrm{~T}_{x}$ an ideal photothermal co-catalyst.

2.2.3 Instability of $\mathbf{T i}_{3} \mathbf{C}_{\mathbf{2}} \mathbf{T}_{\boldsymbol{x}}$. MXenes typically have poor stability. $\mathrm{Ti}_{3} \mathrm{C}_{2} \mathrm{~T}_{x}$ is rapidly oxidized when heated under $\mathrm{CO}_{2}$, air, and other environments, and when the surface groups are all $-\mathrm{O}$, $\mathrm{Ti}_{3} \mathrm{C}_{2} \mathrm{O}_{2}$ exhibits metallic properties. ${ }^{29,30} \mathrm{Ti}_{3} \mathrm{C}_{2} \mathrm{~T}_{x}$ is also slowly oxidized when exposed to air under atmospheric conditions. After oxidation, $\mathrm{Ti}_{3} \mathrm{C}_{2} \mathrm{~T}_{x}$ is called oxidized MXene (denoted as MO).
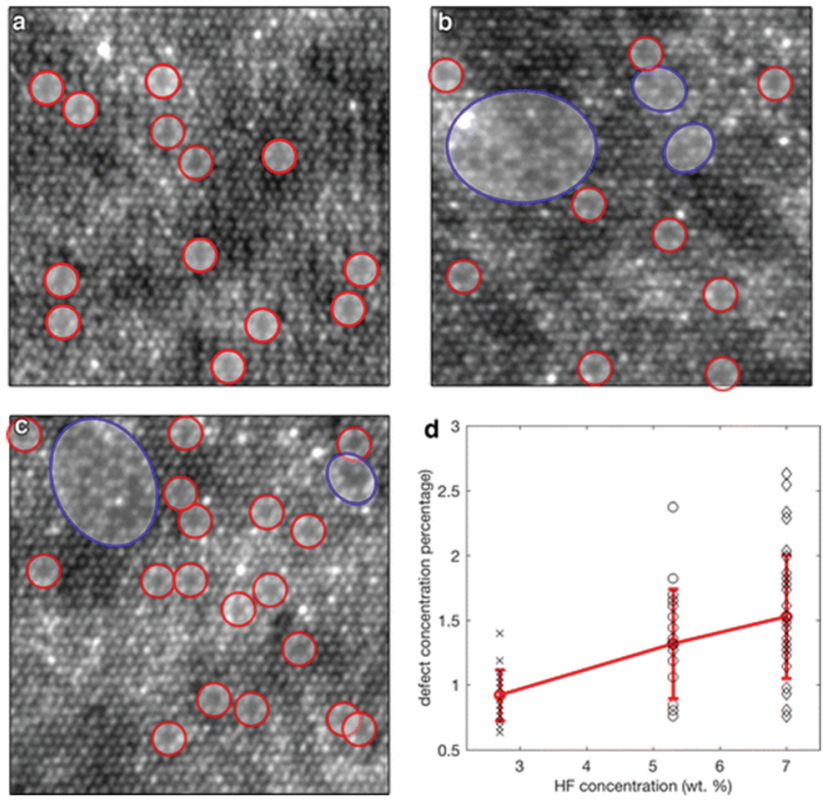

Fig. 4 HAADF-STEM images from single-layer $\mathrm{Ti}_{3} \mathrm{C}_{2} \mathrm{~T}_{x} \mathrm{MXene}$ flakes prepared using etchants with different HF concentrations: (a) 2.7 wt\% HF, (b) 5.3 wt\% HF, and (c) $7 \mathrm{wt} \% \mathrm{HF}$. Single $V_{T_{i}}$ vacancies are indicated by the red circles, while vacancy clusters $V_{T_{i}}^{C}$ are shown by the blue circles. (d) Scatter plot of the defect concentration from the images acquired from samples produced using different HF concentrations. The red line shows the error plot with the average and standard deviation for different HF concentrations. ${ }^{33}$ 


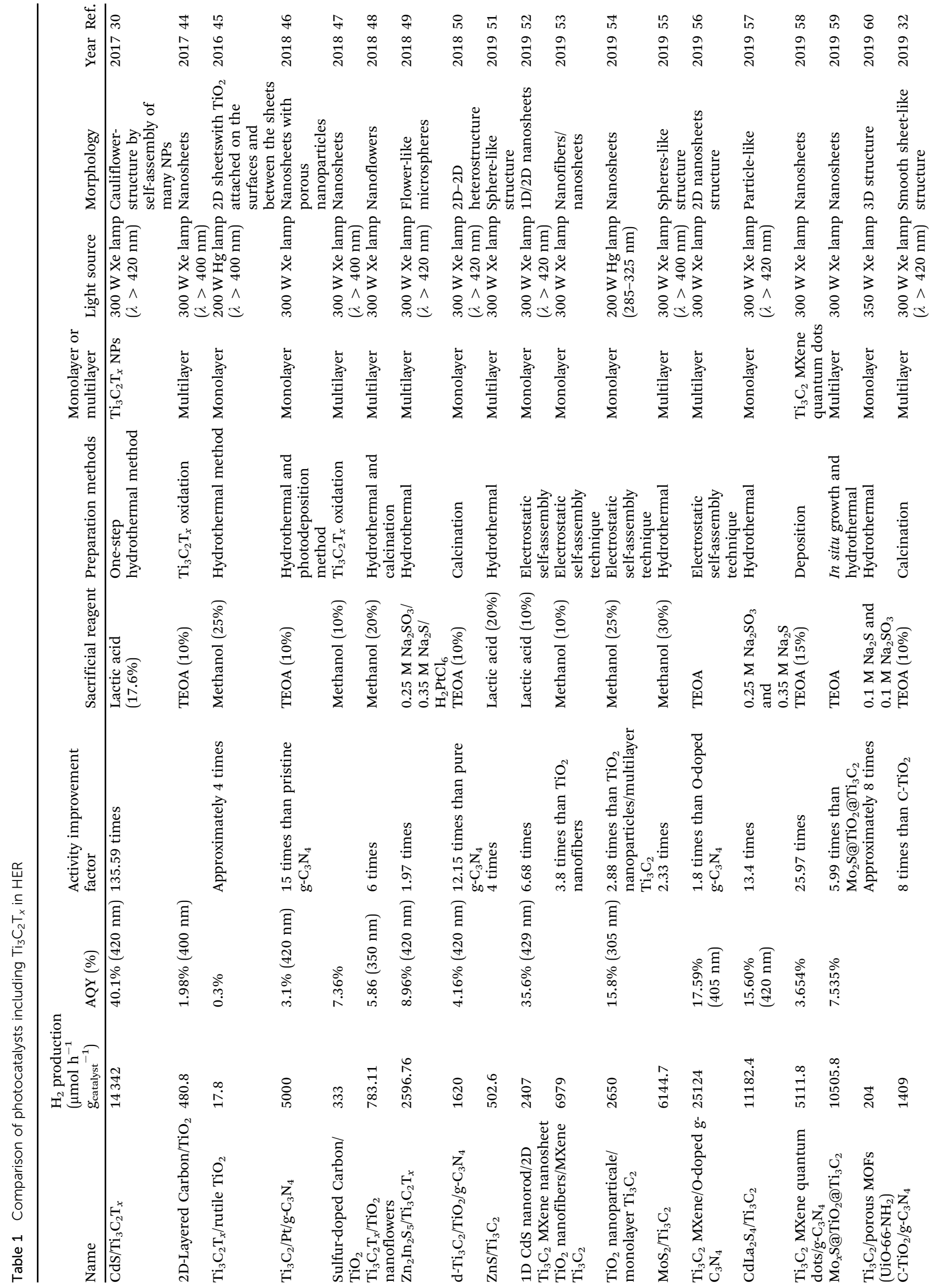




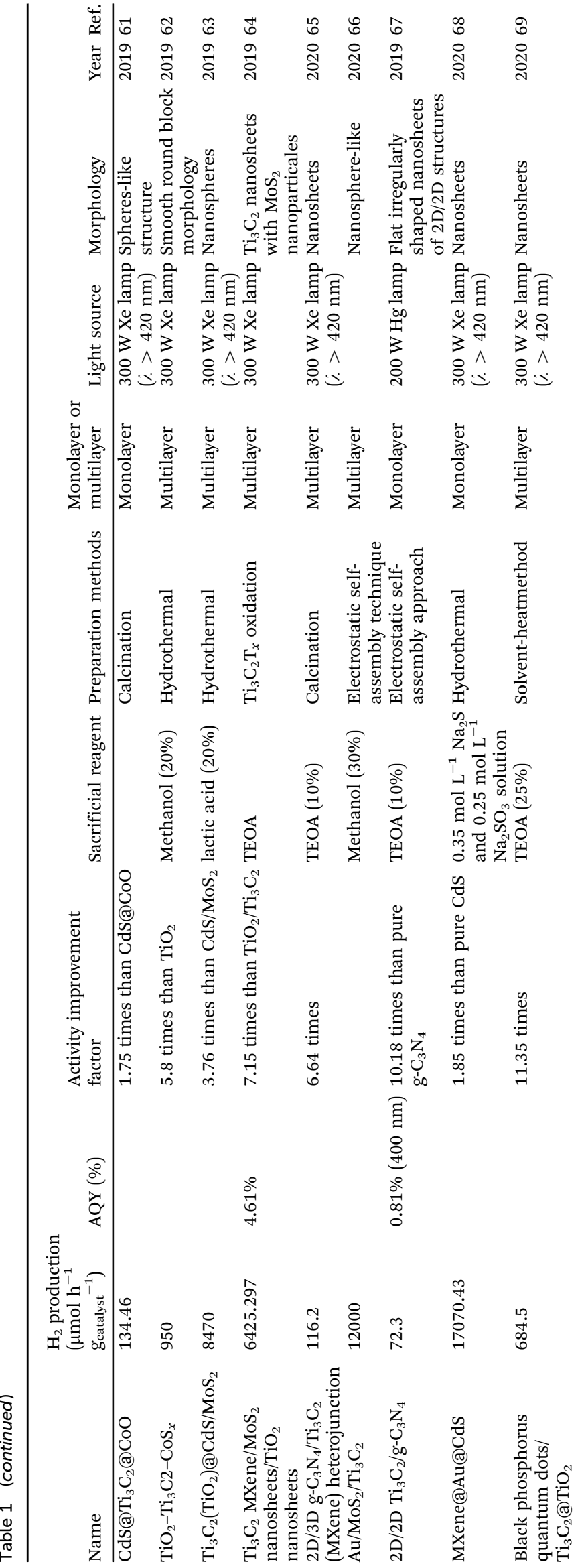



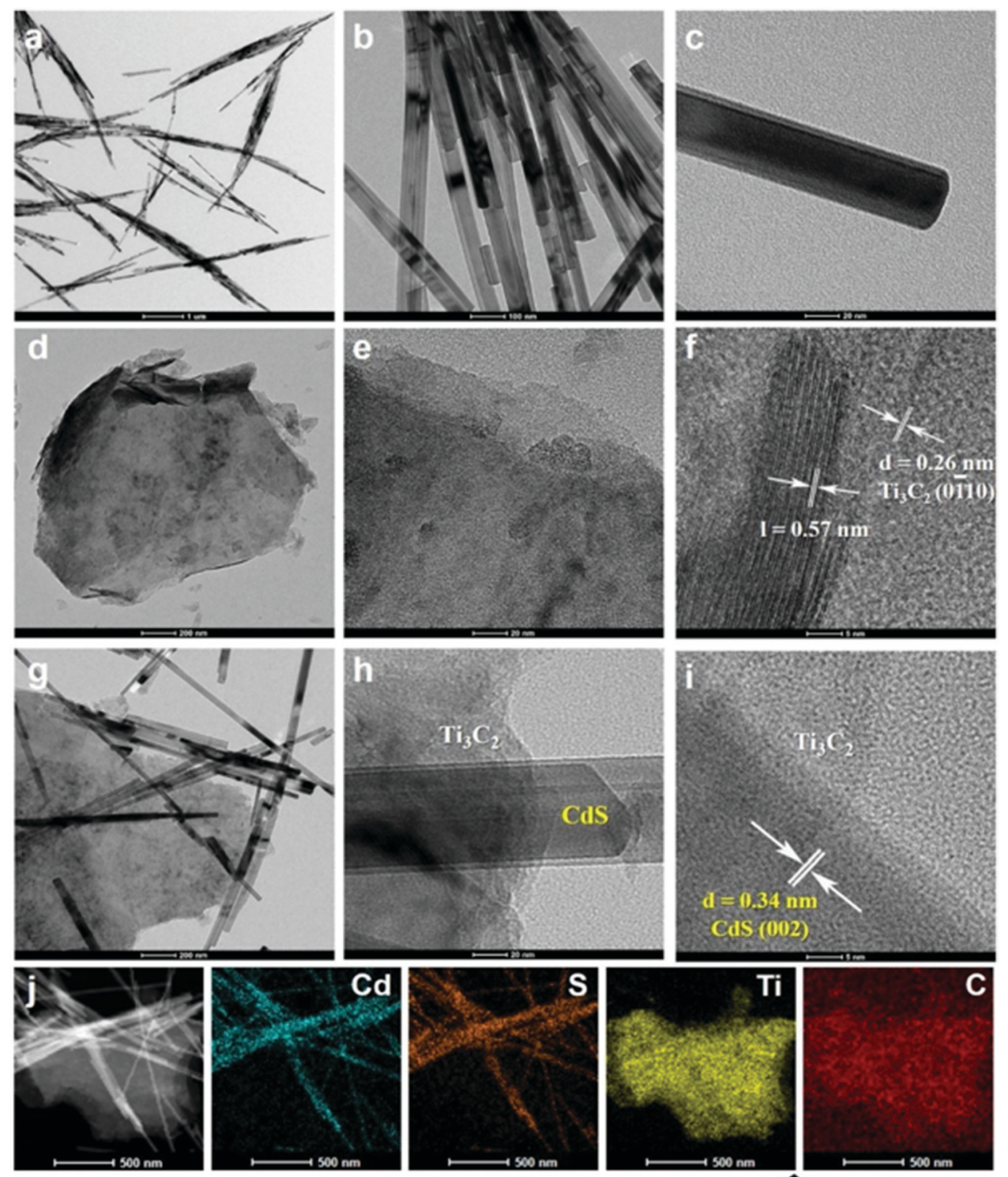

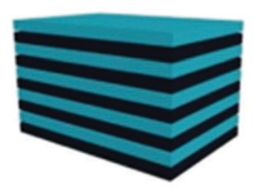

$\mathrm{Ti}_{3} \mathrm{AlC}_{2}$ (MAX)

$\mathbf{k}$

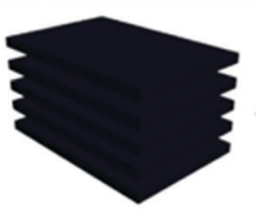

$\mathrm{Ti}_{3} \mathrm{C}_{2}$ (MXene)

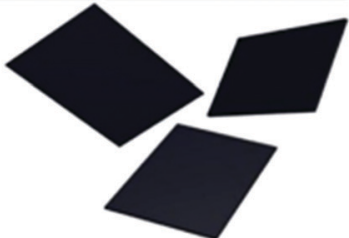

$\mathrm{Ti}_{3} \mathrm{C}_{2}$ (MXene) nanosheets

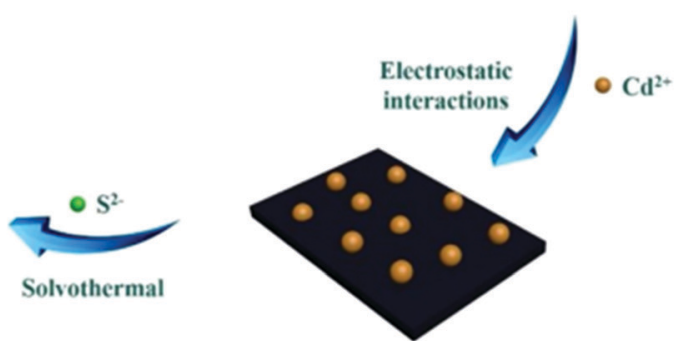

$\mathrm{Cd}^{2+} / \mathrm{Ti}_{3} \mathrm{C}_{2}$ (MXene)

Fig. 5 TEM images of $(a-c) C d S$, $(d-f)$ exfoliated $\mathrm{Ti}_{3} \mathrm{C}_{2}$ MXene nanosheets, $(\mathrm{g}-\mathrm{i})$ the composite $\mathrm{CM}-20$, (j) the corresponding elemental mapping results of $\mathrm{CM}-2 \mathrm{O}$, and $(\mathrm{k})$ the oxidation process of $\mathrm{Ti}_{3} \mathrm{C}_{2} \mathrm{~T}_{x}{ }^{52}$ 

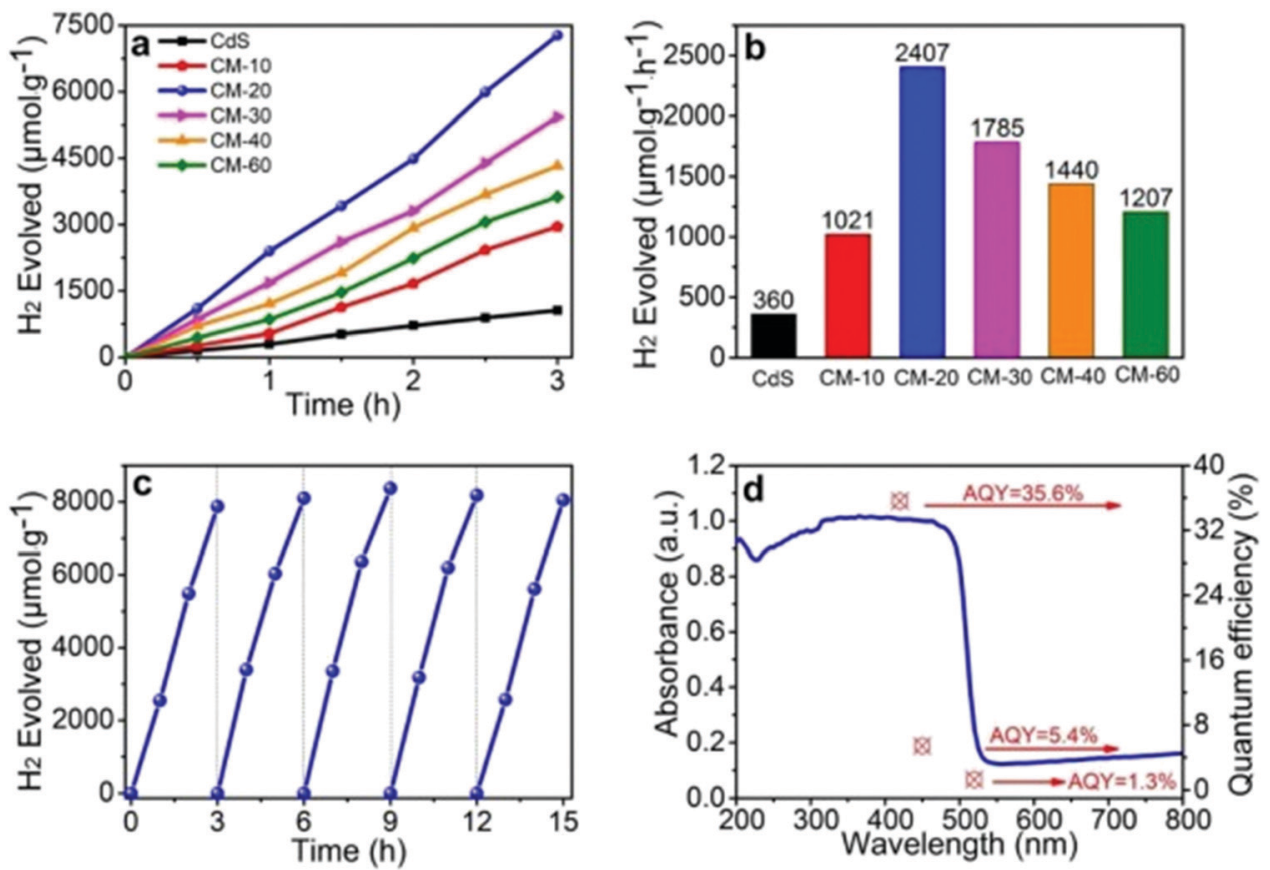

Fig. 6 (a and b) Photocatalytic $\mathrm{H}_{2}$ evolution performance of different samples, (c) the recycled photocatalytic $\mathrm{H}_{2}$ evolution experiments of $\mathrm{CM}-20$, (d) AQY values and the wavelength dependence of photocatalytic $\mathrm{H}_{2}$ evolution in the composite $\mathrm{CM}-20{ }^{52}$

When $\mathrm{Ti}_{3} \mathrm{C}_{2} \mathrm{~T}_{x}$ is oxidized, it is only the Ti atoms that are oxidized into the corresponding oxide $\left(\mathrm{TiO}_{2}\right)$, while the $\mathrm{C}$ atoms remain unchanged. In other words, MO comprises a sandwich structure of layered carbon layers and titanium oxide. ${ }^{31}$ Fig. 3 shows the structural evolution of $\mathrm{Ti}_{3} \mathrm{C}_{2} \mathrm{~T}_{x}$ oxidation to MXene (MO). As can be seen from Fig. 3, MO maintains a layered structure, whilst the $\mathrm{TiO}_{2}$ nanoparticles formed by oxidation are coated within the carbon layer structure. Due to the photoresponse capacity of $\mathrm{TiO}_{2}$, this resulting structure is photocatalytically active. An example of this is $\mathrm{MO} / \mathrm{g}-\mathrm{C}_{3} \mathrm{~N}_{4}$, which can photocatalytically split water with a relatively high efficiency. ${ }^{32}$

The crystal structure of $\mathrm{Ti}_{3} \mathrm{C}_{2} \mathrm{~T}_{x}$ contains $\mathrm{Ti}$ defects, which appear to contribute significantly to the instability of this material. ${ }^{14,33}$ High angle annular dark field (HAADF)-STEM imaging is an important tool in 2D materials' characterization and is used to unambiguously resolve the crystal structure and defect configurations. ${ }^{34,35}$ As shown in Fig. 4, widespread Ti defects were directly detected through the HAADF-STEM imaging of the single-layer $\mathrm{Ti}_{3} \mathrm{C}_{2} \mathrm{~T}_{x}$ flakes. Single-layered $\mathrm{Ti}_{3} \mathrm{C}_{2} \mathrm{~T}_{x}$ obtained by $\mathrm{HF}$ etching was observed through HAADF-STEM images in Fig. 4(a)-(c). Fig. 4(d) was obtained by calculating tens of such images, and it reveals that the relationship between HF concentration and defect formation. It was found that vacancy clusters are rarely observed after etching with $2.7 \mathrm{wt} \% \mathrm{HF}$ concentration but are relatively common after etching with $7 \mathrm{wt} \% \mathrm{HF}^{33}$ Generally speaking, the average concentration of $\mathrm{V}_{\mathrm{Ti}}$ ( $\mathrm{Ti}$ vacancies) is positively related to that of HF.

\section{Application in photocatalysis}

Due to the excellent structural properties of $\mathrm{Ti}_{3} \mathrm{C}_{2} \mathrm{~T}_{x}$, there are many cases in which $\mathrm{Ti}_{3} \mathrm{C}_{2} \mathrm{~T}_{x}$ is used as a co-catalyst in
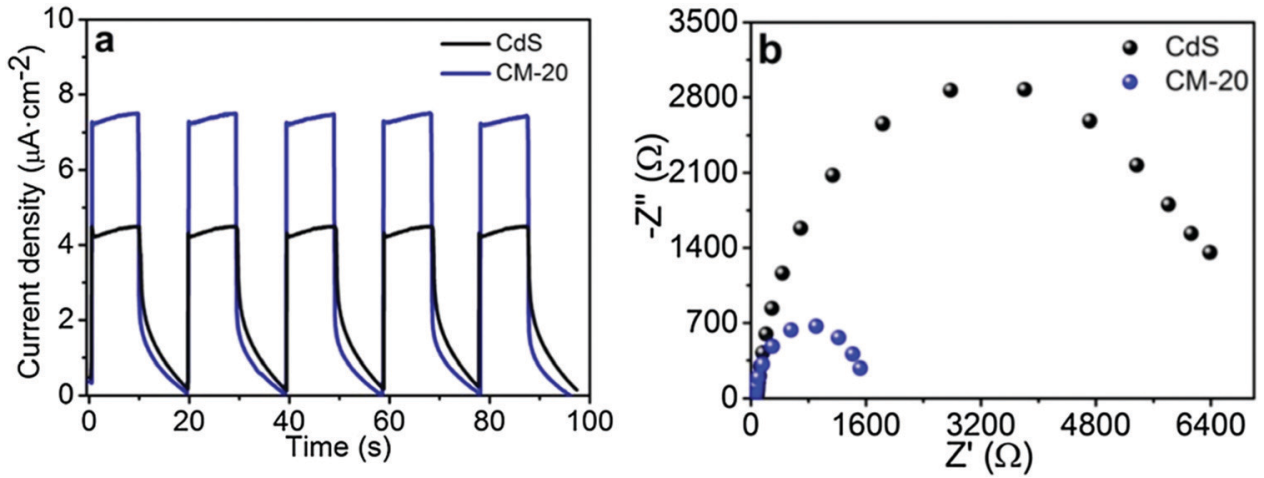

Fig. 7 (a) Photocurrent density curves and (b) EIS Nyquist plots of CdS and CM-20.52 
photocatalytic systems or is directly involved in photocatalytic reaction systems. This paper summarizes the application of $\mathrm{Ti}_{3} \mathrm{C}_{2} \mathrm{~T}_{x}$ in the field of photocatalysis from three aspects: photocatalytic hydrogen evolution reactions (HER), photocatalytic $\mathrm{CO}_{2}$ reduction reactions $\left(\mathrm{CO}_{2} \mathrm{RR}\right)$, and photocatalytic degradation reactions.

\subsection{Application in HER}

$\mathrm{Ti}_{3} \mathrm{C}_{2} \mathrm{~T}_{x}$ is the most widely used photocatalytic agent in hydrogen evolution reactions ${ }^{36-39}$ (HER). $\mathrm{Ti}_{3} \mathrm{C}_{2} \mathrm{~T}_{x}$ has the following advantages that make it ideal for use in photolysis: (a) hydrophilic surface functional groups are conducive for the adsorption of water molecules and promote the reaction; and (b) the Gibbs free energy of $\mathrm{Ti}_{3} \mathrm{C}_{2} \mathrm{~T}_{x}$ adsorption on hydrogen approaches zero infinitely, which is conducive for the reduction of $\mathrm{H}^{+}$.

There are three important steps in the HER process, which are: ${ }^{30,40,41}$ (a) initial $\mathrm{h}^{+}+\mathrm{e}^{-}$formation; (b) generation of $\mathrm{H}^{*}$ (the intermediate adsorption state); and (c) formation of the $1 / 2 \mathrm{H}_{2}$ product. The adsorption state of $\mathrm{H}^{*}$ in process (b) directly affects the final hydrogen evolution efficiency and is an extremely important factor, which can be represented by the Gibbs adsorption free energy $\left|\Delta G_{\mathrm{H}^{*}}\right|$. Through simulation calculations, it was found that when all the $\mathrm{Ti}_{3} \mathrm{C}_{2} \mathrm{~T}_{x}$ surface groups are $-\mathrm{F}, \Delta G_{\mathrm{H}^{*}}=$ $-0.927 \mathrm{eV}$, and the adsorption is too strong. When all the surface groups are $-\mathrm{O},\left|\Delta G_{\mathrm{H}^{*}}\right|$ is $0.003 \mathrm{eV}$, which is even better than the commonly used catalyst $\operatorname{Pt}\left(\Delta G_{\mathrm{H}^{*}} \approx-0.090 \mathrm{eV}\right) .{ }^{42,43}$ Therefore, $\mathrm{Ti}_{3} \mathrm{C}_{2} \mathrm{~T}_{x}$ is a good HER co-catalyst. Examples of $\mathrm{Ti}_{3} \mathrm{C}_{2} \mathrm{~T}_{x}$ used for photolysis in recent years are summarized below (Table 1).

$\mathrm{Ti}_{3} \mathrm{C}_{2} \mathrm{~T}_{x}$ plays a significant role in HER, whether as a co-catalyst or as a part of the overall catalyst, as it greatly improves the performance of the base catalyst. As shown in Table 1, the presence of $\mathrm{Ti}_{3} \mathrm{C}_{2} \mathrm{~T}_{x}$ increases the yield of $\mathrm{H}_{2}$ compared to solely the base catalyst by more than 2 times. The quantum efficiency is also significantly improved to $40.1 \%$, whilst the maximum value of hydrogen production is $14.34 \mathrm{mmol} \mathrm{g}^{-1} \mathrm{~h}^{-1}$.

Monolayer $\mathrm{Ti}_{3} \mathrm{C}_{2} \mathrm{~T}_{x}$ or quantum dot $\mathrm{Ti}_{3} \mathrm{C}_{2} \mathrm{~T}_{x}$ displays better activity in HER. However, the use of monolayer $\mathrm{Ti}_{3} \mathrm{C}_{2} \mathrm{~T}_{x}$ as a photocatalyst has several disadvantages: (a) the preparation of monolayer $\mathrm{Ti}_{3} \mathrm{C}_{2} \mathrm{~T}_{x}$ is complex; (b) the structural stability is low and the catalyst is easily oxidized in water; (c) manipulation of the mono-layer or few-layer structures is not easy to carry out. Few-layer structures are presently prepared by electrostatic selfassembly or by in situ growth. The stability of the composite catalyst obtained by in situ growth is significantly greater than that obtained by electrostatic self-assembly.

Due to the surface hydrophilic groups, ${ }^{70}$ suitable Gibbs adsorption free energies $\left|\Delta G_{\mathrm{H}^{*}}\right|$, and excellent electron transfer efficiency, $\mathrm{Ti}_{3} \mathrm{C}_{2} \mathrm{~T}_{x}$ not only plays an important role in the threestep process of HER but can participate in electron hole separation.

Xiao et al. successfully synthesized the Schottky junction of 1D CdS nanorod/2D $\mathrm{Ti}_{3} \mathrm{C}_{2}$ MXene nanosheet in 2019. ${ }^{52}$ As shown in Fig. 5, Xiao et al. anchored $\mathrm{Cd}^{2+}$ using the deficiency of $\mathrm{Ti}$ on the $\mathrm{Ti}_{3} \mathrm{C}_{2}$ surface and the electrostatic interaction of free $\mathrm{Cd}^{2+}$ to prepare the $1 \mathrm{D} \mathrm{CdS}$ nanorods. The composite material demonstrated excellent hydrogen production performance

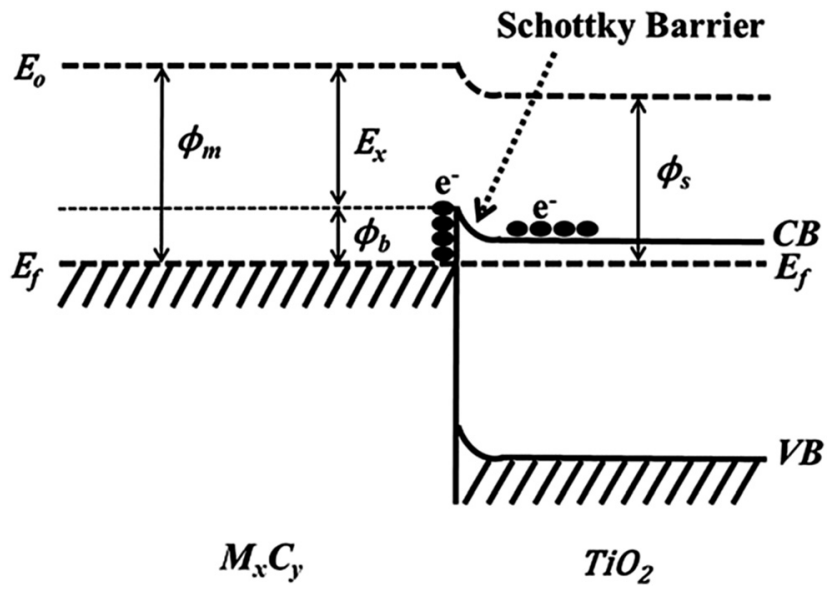

Scheme 1 Formation of Schottky barrier at the $\mathrm{MXene} / \mathrm{TiO}_{2}$ interface. $^{45}$

(2407 $\mu \mathrm{mol} \mathrm{h}{ }^{-1} \mathrm{~g}_{\text {catalyst }}{ }^{-1}$ ), producing 6.68 times as much $\mathrm{H}_{2}$ as pure CdS (Fig. 6).

Theoretically, the surface negative value (zeta potential value: $\sim 18 \mathrm{mV}$ ) of $\mathrm{Ti}_{3} \mathrm{C}_{2} \mathrm{~T}_{x}$ is sufficient to adsorb positively charged $\mathrm{Cd}^{2+} \cdot \mathrm{Ti}_{3} \mathrm{C}_{2} \mathrm{~T}_{x}$ treated with DMSO forms a low-layered structure, on which $\mathrm{Cd}^{2+}$ can be anchored and one-dimensional CdS nanorods can be grown. As shown in Fig. 5, due to the constraint effect of $\mathrm{Ti}_{3} \mathrm{C}_{2} \mathrm{~T}_{x}$, the length of $1 \mathrm{D} \mathrm{CdS}$ nanorods in the $1 \mathrm{D} \mathrm{CdS}$ nanorods/2D $\mathrm{Ti}_{3} \mathrm{C}_{2} \mathrm{~T}_{x}$ heterojunctions is smaller than that of the $1 \mathrm{D}$ CdS nanorods alone.

CdS equipped with $\mathrm{Ti}_{3} \mathrm{C}_{2} \mathrm{~T}_{x}$ displays excellent electrochemical properties. As shown in Fig. 7, the photocurrent of $1 \mathrm{D} \mathrm{CdS}$ nanorods/2D $\mathrm{Ti}_{3} \mathrm{C}_{2} \mathrm{~T}_{x}$ was significantly better than that of onedimensional CdS nanorods and the optical resistance was significantly lower than that of one-dimensional CdS nanorods. ESR tests show that the hydroxyl radical and superoxide radical signals of $1 \mathrm{D} \mathrm{CdS}$ nanorods/2D $\mathrm{Ti}_{3} \mathrm{C}_{2} \mathrm{~T}_{x}$ were significantly enhanced after the addition of $\mathrm{Ti}_{3} \mathrm{C}_{2} \mathrm{~T}_{x}$. In conclusion, under the same illumination conditions, $1 \mathrm{D}$ CdS nanorods $/ 2 \mathrm{D} \mathrm{Ti}_{3} \mathrm{C}_{2} \mathrm{~T}_{x}$ generate more photogenic carriers. These produce oxygen-containing
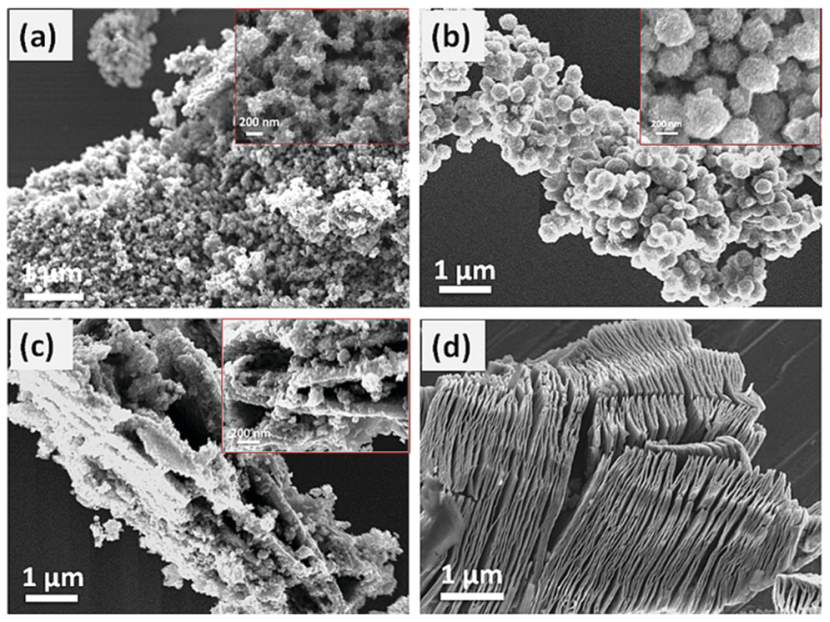

Fig. 8 SEM images of (a) $\mathrm{TiO}_{2}\left(50\right.$ wt\%), (d) $\mathrm{Ti}_{3} \mathrm{C}_{2} \mathrm{~T}_{x}$, (b) $\mathrm{TiO}_{2} / \mathrm{Ti}_{3} \mathrm{C}_{2} \mathrm{~T}_{x}$ (5 wt\%), and (c) $\mathrm{TiO}_{2} / \mathrm{Ti}_{3} \mathrm{C}_{2} \mathrm{~T}_{x} \cdot{ }^{45}$ 

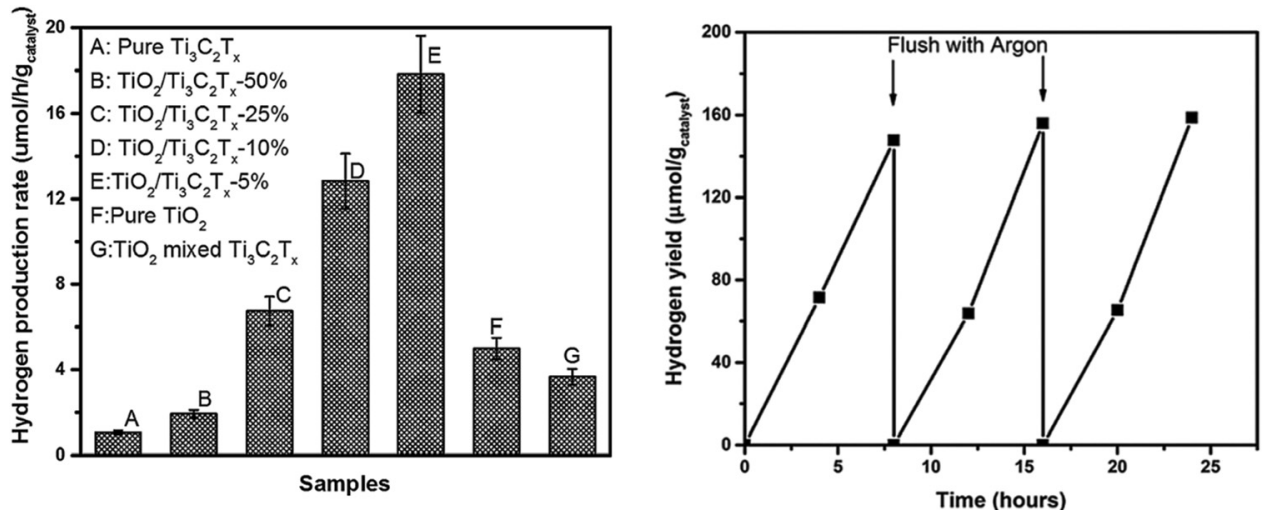

Fig. 9 (a) Photocatalytic hydrogen production rates and (b) recycling studies over the $\mathrm{TiO}_{2} / \mathrm{Ti}_{3} \mathrm{C}_{2} \mathrm{~T}_{x}\left(5\right.$ wt\%) sample. ${ }^{45}$

groups with oxidizing reductivity, which can participate in photocatalytic hydrogenation reactions.

1D CdS nanorods/2D $\mathrm{Ti}_{3} \mathrm{C}_{2} \mathrm{~T}_{x}$ typically exhibit better visible light response, electron hole separation efficiency, and more effective carrier transport efficiency after the formation of multi-dimensional heterojunctions. This accounts for their excellent photocatalytic hydrogen evolution capability.

Using $\mathrm{Ti}_{3} \mathrm{C}_{2} \mathrm{~T}_{x}$ as the co-catalyst, Wang et al. synthesized a $\mathrm{TiO}_{2} / \mathrm{Ti}_{3} \mathrm{C}_{2} \mathrm{~T}_{x}$ complex photocatalyst, ${ }^{45}$ which was 4 times more efficient than pure phase $\mathrm{TiO}_{2}$ in photohydrolyzing aquatic hydrogen. This is attributed to the Schottky barrier formed between $\mathrm{TiO}_{2}$ and $\mathrm{Ti}_{3} \mathrm{C}_{2} \mathrm{~T}_{x}$, which effectively improves the separation efficiency of the electron holes. As shown in Scheme 1, excited electrons can be wired to $\mathrm{Ti}_{3} \mathrm{C}_{2} \mathrm{~T}_{x}$ from the conduction band of $\mathrm{TiO}_{2}$ owing to the close contact between $\mathrm{Ti}_{3} \mathrm{C}_{2} \mathrm{~T}_{x}$ and $\mathrm{TiO}_{2}$; thus, negative charge is accumulated in $\mathrm{Ti}_{3} \mathrm{C}_{2} \mathrm{~T}_{x}$ and a depletion layer formed at the metal-semiconductor interface, which is the Schottky barrier. ${ }^{45}$

In this work, Wang et al. treated $\mathrm{Ti}_{3} \mathrm{C}_{2} \mathrm{~T}_{x}$ with DMSO to form low-layer structures. Amorphous $\mathrm{TiO}_{2}$ was formed from $\mathrm{TiCl}_{4}$ hydrolysis and then on the surface of $\mathrm{Ti}_{3} \mathrm{C}_{2} \mathrm{~T}_{x}$, amorphous $\mathrm{TiO}_{2}$ was coated. After hydrothermal treatment, anatase $\mathrm{TiO}_{2} / \mathrm{Ti}_{3} \mathrm{C}_{2} \mathrm{~T}_{x}$ material was formed, as shown in Fig. 8. Amorphous $\mathrm{TiO}_{2}$ is micro-spherical and is coated on the surface of $\mathrm{Ti}_{3} \mathrm{C}_{2} \mathrm{~T}_{x}$, displaying

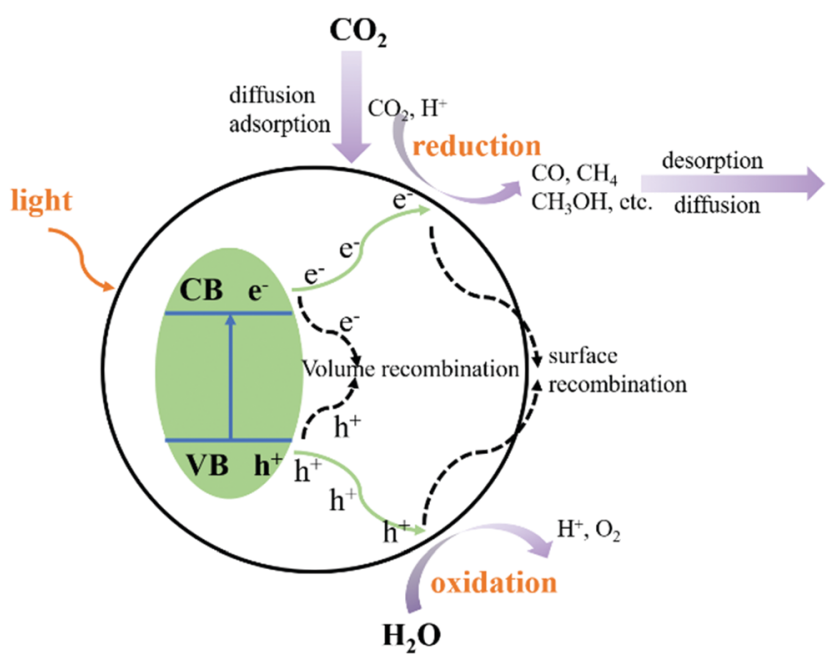

Fig. $11 \mathrm{CO}_{2} \mathrm{RR}$ process.

a low-layered structure (Fig. 8). After water heat treatment, the whole structure forms into a brittle cake structure (Fig. 9).

The $\mathrm{TiO}_{2} / \mathrm{Ti}_{3} \mathrm{C}_{2} \mathrm{~T}_{x}$ material displays excellent photocatalytic hydrogen evolution capability with good cycling stability. The hydrogen production efficiency of $\mathrm{TiO}_{2} / \mathrm{Ti}_{3} \mathrm{C}_{2} \mathrm{~T}_{x}-5 \%$ is about 4 times as high as
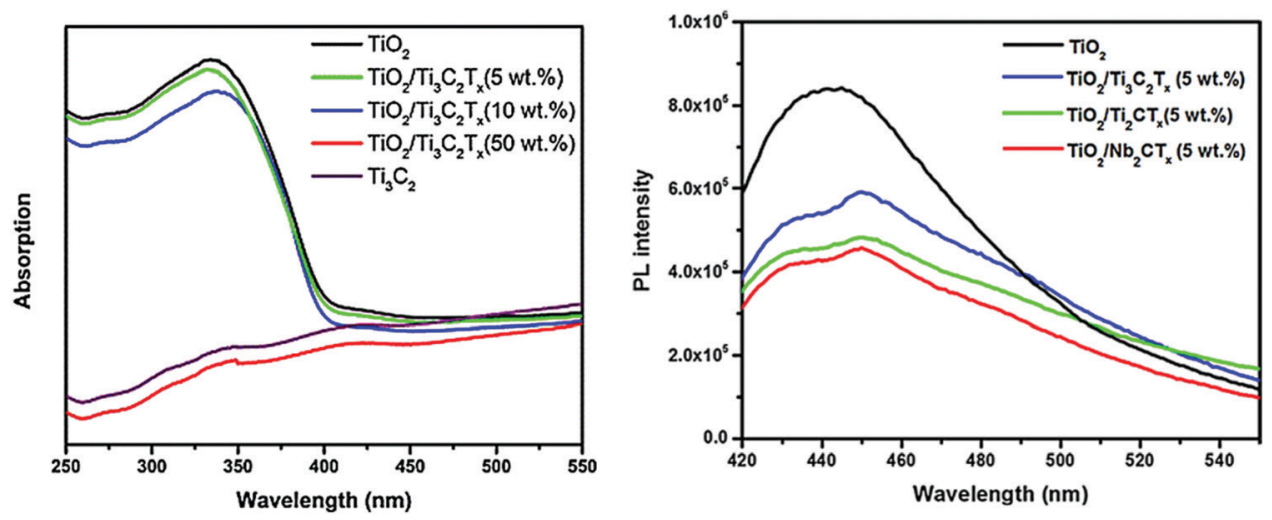

Fig. 10 (a) PL spectra and (b) DRS spectra of $\mathrm{TiO}_{2}, \mathrm{TiO}_{2} / \mathrm{Ti}_{3} \mathrm{C}_{2} \mathrm{~T}_{x}(5 \mathrm{wt} \%), \mathrm{TiO}_{2} / \mathrm{Ti}_{3} \mathrm{C}_{2} \mathrm{~T}_{x}\left(10 \mathrm{wt} \%\right.$ ), and $\mathrm{TiO}_{2} / \mathrm{Ti}_{3} \mathrm{C}_{2} \mathrm{~T}_{x}(50 \mathrm{wt} \%)$. ${ }^{45}$ 


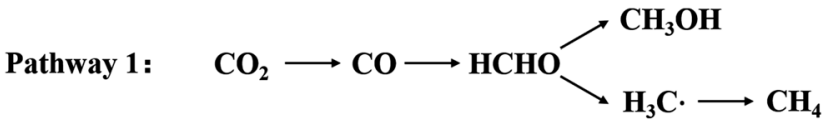

Pathway 2: $\mathrm{CO}_{2} \longrightarrow \mathrm{HCOOH} \longrightarrow \mathrm{HCHO}+\mathrm{H}_{2} \mathrm{O}$

Fig. 12 Two pathways in $\mathrm{CO}_{2} \mathrm{RR}$.

that of pure phase $\mathrm{TiO}_{2}$, reaching $17.8 \mu \mathrm{mol} \mathrm{h}^{-1} \mathrm{~g}_{\text {catalyst }}{ }^{-1}$. The hydrogen production efficiency of the $10 \%$ and $50 \%$ samples decreased slightly, which may be related to light energy absorption, as shown in Fig. 10(a). With the increase in $\mathrm{Ti}_{3} \mathrm{C}_{2} \mathrm{~T}_{x}$ addition, the light absorption capacity of the samples in the 250-380 $\mathrm{nm}$ region is gradually decreased. This significant improvement in the hydrogen production efficiency is closely related to the smooth carriage of $\mathrm{Ti}_{3} \mathrm{C}_{2} \mathrm{~T}_{x}$. As shown in Fig. 10(b), after the formation of the Schottky barrier, the carrier separation efficiency is improved, thus improving its photocatalytic capacity.

Thus, in conclusion, after loading with $\mathrm{Ti}_{3} \mathrm{C}_{2} \mathrm{~T}_{x}, \mathrm{H}_{2}$ production increased at least twice. Such an amazing promotion is mainly related with 3 aspects of $\mathrm{Ti}_{3} \mathrm{C}_{2} \mathrm{~T}_{x}$ : (a) it supplies a high throughput channel as a co-catalyst for the excited electrons while the holes cannot pass the boundaries; (b) its hydrophilcity; and (c) the Gibbs free energy of $\mathrm{Ti}_{3} \mathrm{C}_{2} \mathrm{~T}_{x}$ adsorption on hydrogen approaches zero infinitely.

\subsection{Application in $\mathrm{CO}_{2} \mathrm{RR}$}

The photocatalytic $\mathrm{CO}_{2}$ reduction reaction $\left(\mathrm{CO}_{2} \mathrm{RR}\right)$ consists of five steps: ${ }^{71-74}$ light absorption, charge separation, $\mathrm{CO}_{2}$ adsorption, surface redox reaction, and product desorption. As shown in Fig. 11, when the $\mathrm{CB}$ of the photocatalyst is greater than the redox potential of $\mathrm{CO}_{2}$, and charge separation occurs whilst the electrons and holes recombine. Several complex factors dictate which of these two competing processes predominantly occurs. After the adsorption of $\mathrm{CO}_{2}$ and the migration of photogenerated electrons and holes from the inside of the crystal structure to the surface, the redox reaction is carried out on the surface of the catalyst. The product then de-attaches, which completes the entire photocatalytic $\mathrm{CO}_{2}$ reduction reaction.

$\mathrm{Ti}_{3} \mathrm{C}_{2} \mathrm{~T}_{x}$ is also widely used in the photocatalytic $\mathrm{CO}_{2}$ reduction reaction. However, due to its own carbon source and instability, further research is needed to understand the mechanism of photocatalytic $\mathrm{CO}_{2}$ reduction of $\mathrm{Ti}_{3} \mathrm{C}_{2} \mathrm{~T}_{x}$.

In 2017, Zhang et al. summarized the $\mathrm{CO}_{2}$ reduction capacity of three MXene materials with surface groups, which terminate with $-\mathrm{O}$ through theoretical calculations. ${ }^{75}$ Among the three materials, $\mathrm{Ti}_{2} \mathrm{CO}_{2}, \mathrm{~V}_{2} \mathrm{CO}_{2}$, and $\mathrm{Ti}_{3} \mathrm{C}_{2} \mathrm{O}_{2}, \mathrm{Ti}_{2} \mathrm{CO}_{2}$ showed the best photocatalytic $\mathrm{CO}_{2}$ reduction capacity. Of the two reduction paths ${ }^{76-78}$ shown in Fig. 12, the pathway of " $\mathrm{CO}_{2}-\mathrm{HCOO}-$ $\mathrm{HCOOH}$ " has a favorable energy barrier of about $0.53 \mathrm{eV}$.

Through DFT calculations, it was revealed that in the first step reaction of $\mathrm{CO}_{2}$ adsorption in $\mathrm{CO}_{2} \mathrm{RR}$, the $\mathrm{O}$ atom of the $\mathrm{CO}_{2}$ molecule occupies an O defect position on the MXene. This mode in adsorption requires the lowest energy. The adsorption energies of the three materials were $\mathrm{Ti}_{3} \mathrm{C}_{2} \mathrm{O}_{2}(-0.73 \mathrm{eV}), \mathrm{Ti}_{2} \mathrm{CO}_{2}$ $(-0.67 \mathrm{eV})$, and $\mathrm{V}_{2} \mathrm{CO}_{2}(-0.35 \mathrm{eV}) . \mathrm{Ti}_{2} \mathrm{CO}_{2}$ has a lower adsorption energy compared to $\mathrm{V}_{2} \mathrm{CO}_{2}$ as the Ti atoms are more likely to lose electrons than the $\mathrm{V}$ atoms.

If the reaction proceeds via pathway 1 (Fig. 11), one of the oxygen atoms of the $\mathrm{CO}_{2}$ molecule is captured by the oxygen defect. This results in the breaking of the $\mathrm{C}-\mathrm{O}$ bond, while $\mathrm{CO}$ is produced. In this step, $\mathrm{Ti}_{3} \mathrm{C}_{2} \mathrm{O}_{2}$ would lower the energy barrier of the $\mathrm{C}-\mathrm{O}$ bond to about $0.86 \mathrm{eV}$. Pathway 2 (Fig. 11) has an energy barrier greater than $1 \mathrm{eV}$. In this pathway, the $\mathrm{CO}_{2}$ molecules are captured by an oxygen defect on the surface of MXene and are hydrogenated to form $\mathrm{COOH}$. This is further hydrogenated and converted into the products $\mathrm{CO}$ and $\mathrm{H}_{2} \mathrm{O}$. $\mathrm{CO}$, which is produced, can further react to form $\mathrm{HCOOH}$, $\mathrm{HCOH}, \mathrm{CH}_{2} \mathrm{OH}, \mathrm{CH}_{4}$, and other products.

Studies into the application of $\mathrm{Ti}_{3} \mathrm{C}_{2} \mathrm{~T}_{x}$ in $\mathrm{CO}_{2} \mathrm{RR}$ is summarized in Table 2.

In 2018, Cao et al. prepared a 2D/2D heterogeneous junction of $\mathrm{Ti}_{3} \mathrm{C}_{2} \mathrm{~T}_{x} / \mathrm{Bi}_{2} \mathrm{WO}_{6}$ and the composite showed excellent photocatalytic $\mathrm{CO}_{2}$ reduction performance. ${ }^{82}$ As shown in Fig. 13,

Table 2 Comparison of photocatalysts including $\mathrm{Ti}_{3} \mathrm{C}_{2} \mathrm{~T}_{x}$ in $\mathrm{CO}_{2} \mathrm{RR}$

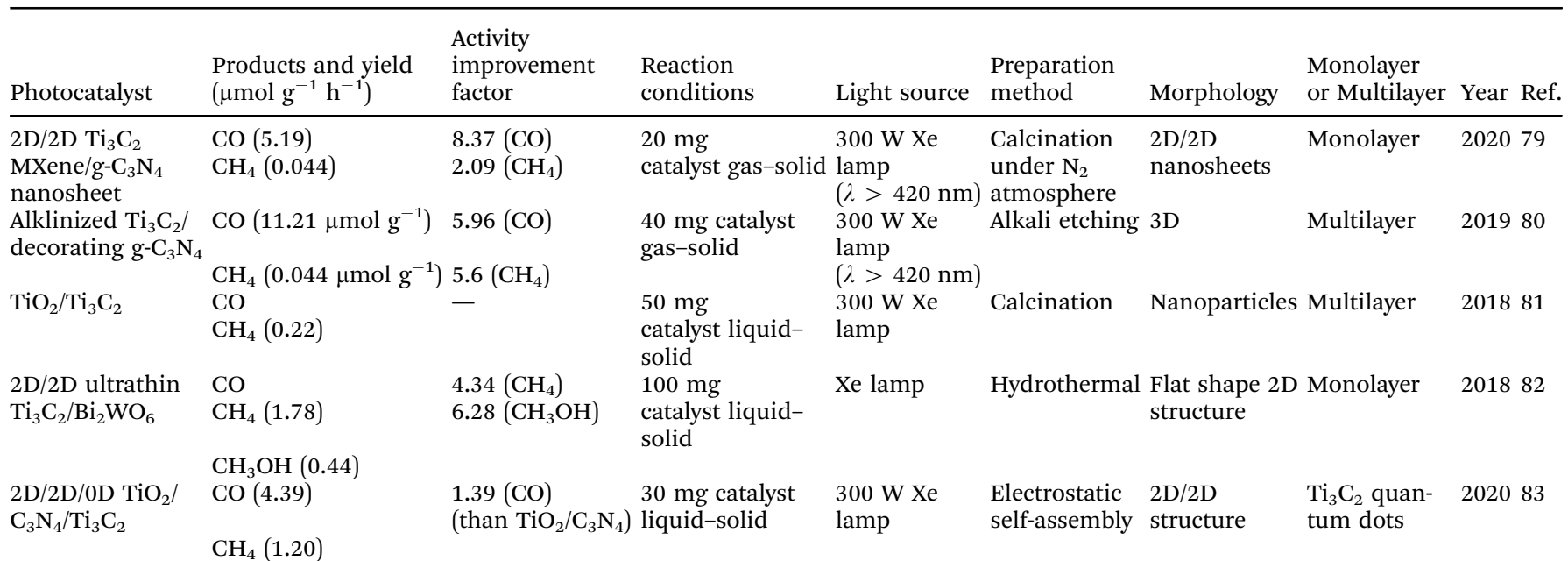



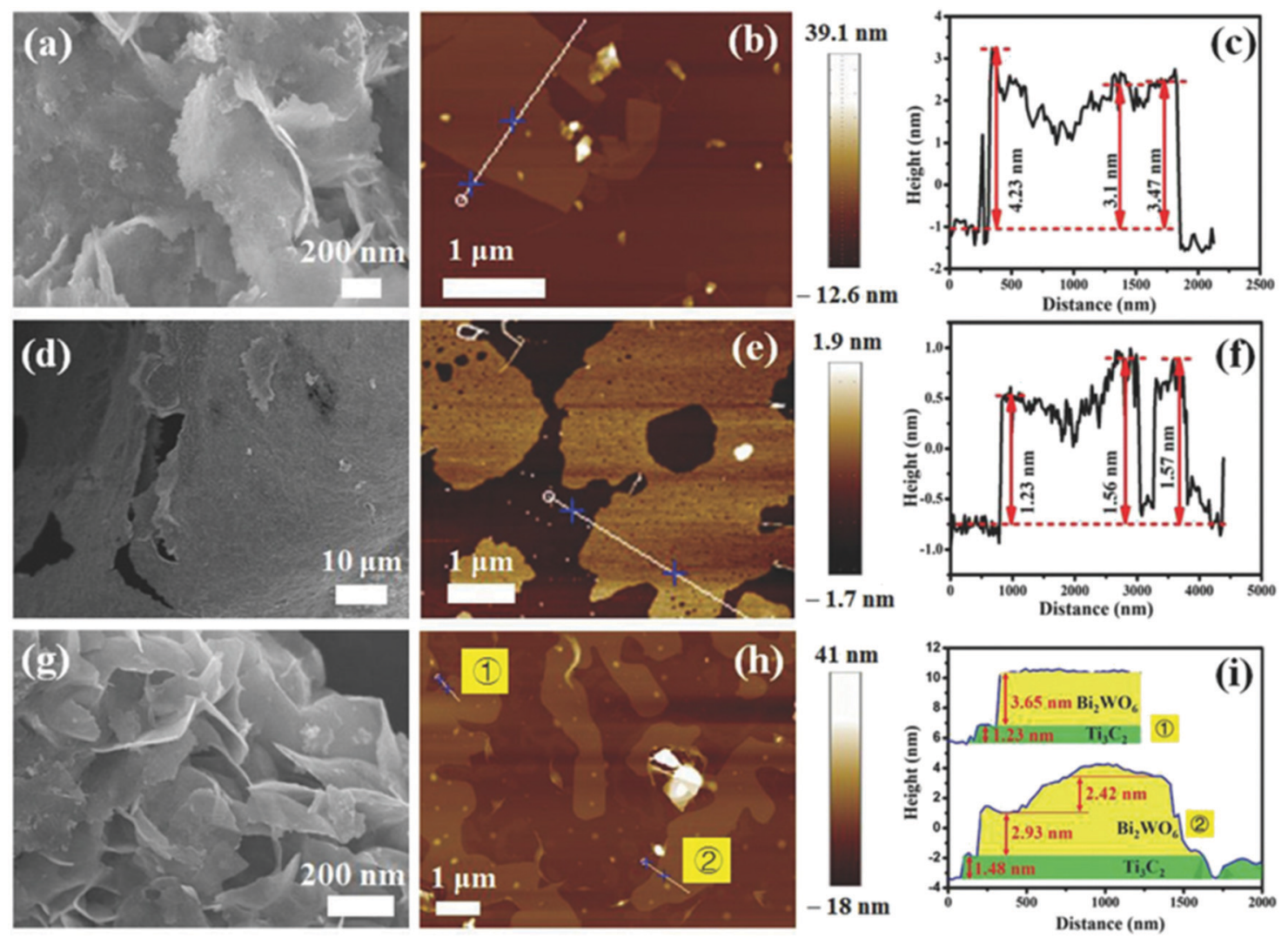

(j)

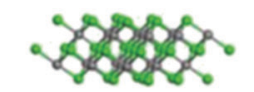

$-\infty+\infty 40 \%$ HF

s.8s\% etching

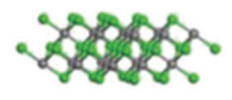

$-\infty+\infty+$ Room temperature

aspor.

$72 \mathrm{~h}$

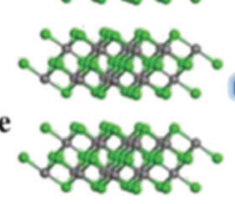

DMSO

$\mathrm{Ti}_{3} \mathrm{AlC}_{2}$ MAX phase

Multilayer $\mathrm{Ti}_{3} \mathrm{C}_{2}$

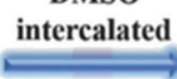

Ultrasonic

exfoliation

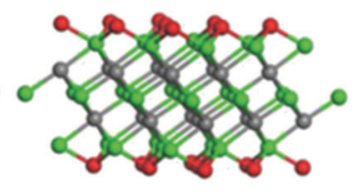

$\mathrm{Ti}_{3} \mathrm{C}_{2}$ nanosheets

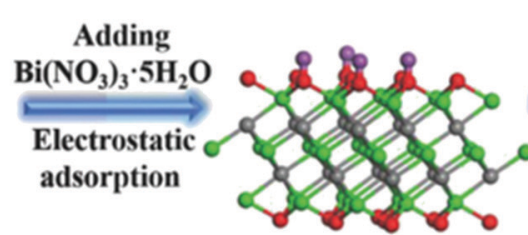

$\mathrm{Bi}^{3+} / \mathrm{Ti}_{3} \mathrm{C}_{2}$

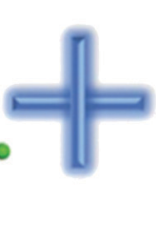

$\mathrm{Na}_{2} \mathrm{WO}_{4} \cdot 2 \mathrm{H}_{2} \mathrm{O} / \mathrm{CTAB}$

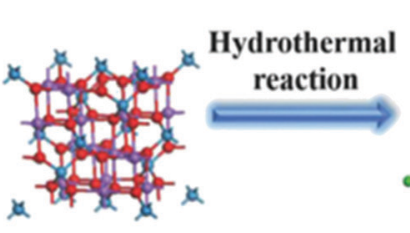

$\mathrm{Ti}_{3} \mathrm{C}_{2} / \mathrm{Bi}_{2} \mathrm{WO}_{6} 2 \mathrm{D} / 2 \mathrm{D}$ structure

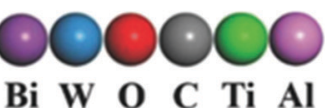

Fig. 13 (a-c) Typical FESEM, AFM images, and height cutaway view of $\mathrm{Bi}_{2} \mathrm{WO}_{6}$, (d-f) $\mathrm{Ti}_{3} \mathrm{C}_{2}$ nanosheets, $(\mathrm{g}-\mathrm{i}) \mathrm{TB}_{2}\left(\mathrm{Ti}_{3} \mathrm{C}_{2} \mathrm{~T}_{x} / \mathrm{Bi}_{2} \mathrm{WO}_{6}\right)$, and (j) schematic illustration of the synthetic process. ${ }^{82}$

multi-layer structure $\mathrm{Ti}_{3} \mathrm{C}_{2} \mathrm{~T}_{x}$ was tested with DMSO. After the formation of low-layer structure $\mathrm{Ti}_{3} \mathrm{C}_{2} \mathrm{~T}_{x}$, the oxygen-rich surface was negatively charged, which permitted $\mathrm{Bi}^{3+}$ to be adsorbed from hydrolyzed $\mathrm{Bi}\left(\mathrm{NO}_{3}\right)_{35} 5 \mathrm{H}_{2} \mathrm{O} .{ }^{84}$ After the addition of a tungsten source, a $2 \mathrm{D} / 2 \mathrm{D} \quad \mathrm{Ti}_{3} \mathrm{C}_{2} \mathrm{~T}_{x} / \mathrm{Bi}_{2} \mathrm{WO}_{6}$ heterojunction was formed. The concurrent addition of CTAB furthermore ensures the ultrathin structure of both $\mathrm{Bi}_{2} \mathrm{WO}_{6}{ }^{85}$ and $\mathrm{Ti}_{3} \mathrm{C}_{2} \mathrm{~T}_{x}{ }^{86}$

The successful preparation of heterojunctions greatly enhances the ability of $\mathrm{Bi}_{2} \mathrm{WO}_{6}$ to reduce $\mathrm{CO}_{2}$. The $\mathrm{CH}_{4}$ production of the sample TB2 reached $1.78 \mu \mathrm{mol} \mathrm{h}^{-1} \mathrm{~g}^{-1}$, while 
定
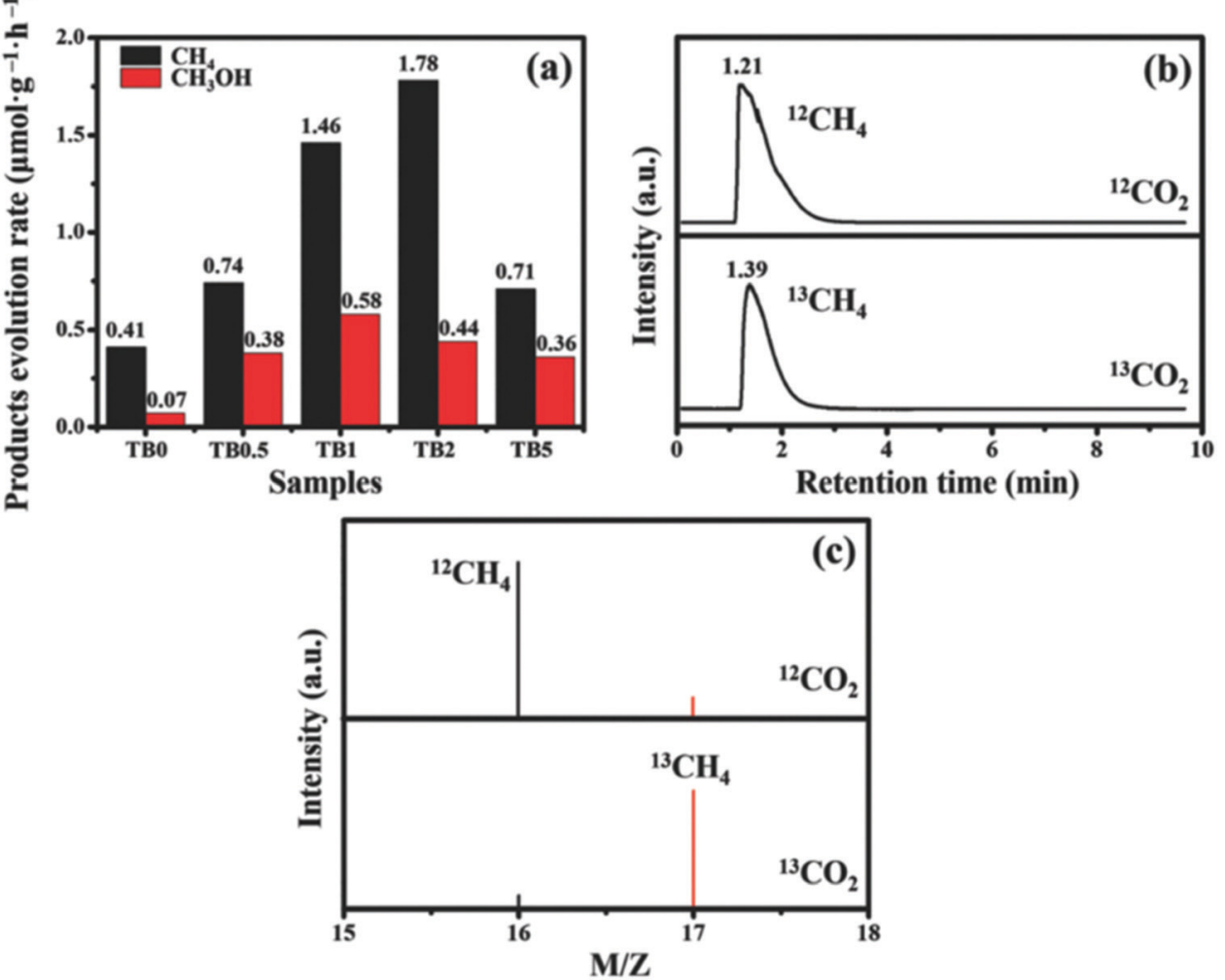

Fig. 14 (a) Photocatalytic activity of TB0 to TB5; (b) GC-MS spectra over TB2 after irradiation for several hours with different carbon sources; (c) GC-MS analysis of the reaction products with ${ }^{12} \mathrm{C}$ and ${ }^{13} \mathrm{C}$ as carbon sources. ${ }^{82}$
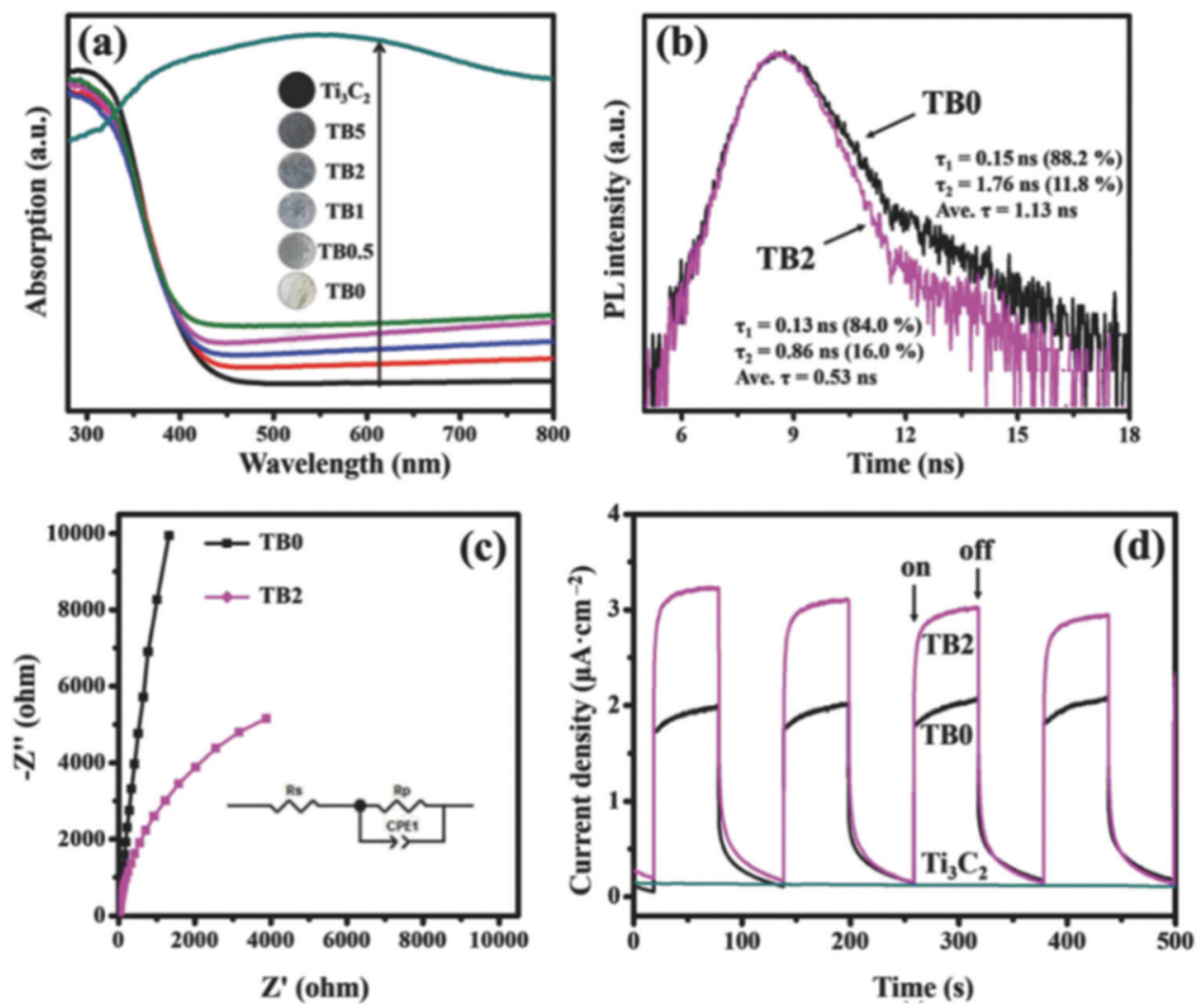

Fig. 15 (a) UV-Vis DRS of all the as-prepared samples; (b) TRPL spectra of TBO and TB2; (c) EIS plots and (d) transient photocurrent of the prepared samples. ${ }^{82}$ 
the yield of $\mathrm{CH}_{3} \mathrm{OH}$ reached $0.44 \mu \mathrm{mol} \mathrm{h} \mathrm{h}^{-1} \mathrm{~g}^{-1}$. The isotopic spectra of Fig. 14(b) and (c) indicates that the produced $\mathrm{CH}_{4}$ and $\mathrm{CH}_{3} \mathrm{OH}$ are formed from the photocatalytic reduction of $\mathrm{CO}_{2}$.

As shown in Fig. 15(a), $\mathrm{Ti}_{3} \mathrm{C}_{2} \mathrm{~T}_{x}$ exhibits excellent light absorption performance between 200-800 $\mathrm{nm}$. The light absorption capacity of $\mathrm{Bi}_{2} \mathrm{WO}_{6}$ was also significantly improved by carrying $\mathrm{Ti}_{3} \mathrm{C}_{2} \mathrm{~T}_{x}$. To be noted, as shown in Fig. 14(b), the fluorescence lifetime decreased after loading with $\mathrm{Ti}_{3} \mathrm{C}_{2} \mathrm{~T}_{x}$. This is because TC supplies a more efficient non-radiative decay pathway. In electrochemical tests, the photocurrent photoelectric impedance spectrum further revealed that the carriage of $\mathrm{Ti}_{3} \mathrm{C}_{2} \mathrm{~T}_{x}$ greatly promoted the carrier strength of $\mathrm{Bi}_{2} \mathrm{WO}_{6}$. This further confirmed the successful construction of the $\mathrm{Ti}_{3} \mathrm{C}_{2} \mathrm{~T}_{x} / \mathrm{Bi}_{2} \mathrm{WO}_{6}$ heterojunction.
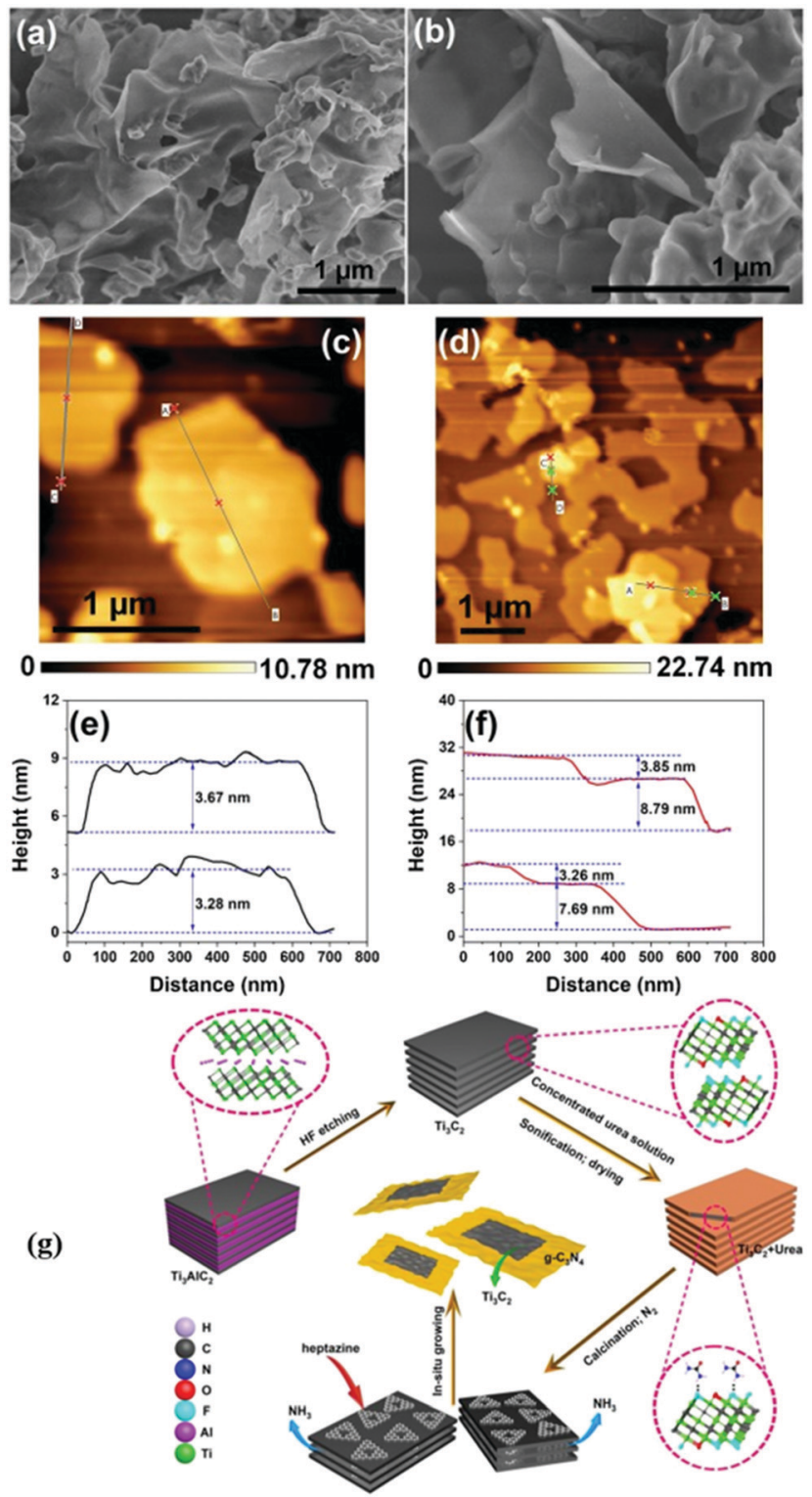

Fig. 16 FESEM images of UCN (a) and 10TC (b) samples, AFM images and the corresponding height profiles of UCN ( $c$ and e), 10TC ( $d$ and f) samples, and $(\mathrm{g})$ schematic illustration for the fabrication process. ${ }^{79}$
Yang et al. prepared $2 \mathrm{D} / 2 \mathrm{D} \mathrm{Ti} \mathrm{C}_{2}$ MXene/g- $\mathrm{C}_{3} \mathrm{~N}_{4}$ heterojunctions in $2020 .^{79}$ As shown in Fig. $16(\mathrm{~g}), \mathrm{Ti}_{3} \mathrm{AlC}_{2}$ was successfully etched to form $\mathrm{Ti}_{3} \mathrm{C}_{2}$, as indicated by the XRD patterns. ${ }^{87,88} 2 \mathrm{D}$ $\mathrm{g}-\mathrm{C}_{3} \mathrm{~N}_{4}$ was found to grow on the surface of $\mathrm{Ti}_{3} \mathrm{C}_{2}$ under an atmosphere of $\mathrm{N}_{2}$. The formed $2 \mathrm{D} / 2 \mathrm{D} \quad \mathrm{Ti}_{3} \mathrm{C}_{2}$ MXene/g- $\mathrm{C}_{3} \mathrm{~N}_{4}$ demonstrated excellent photocatalytic $\mathrm{CO}_{2}$ reduction capability. As shown in Fig. 17, the photocatalytic performance of pure phase g- $\mathrm{C}_{3} \mathrm{~N}_{4}$ for the production of $\mathrm{CO}$ and $\mathrm{CH}_{4}$ is only $0.62 \mu \mathrm{mol} \mathrm{h} \mathrm{h}^{-1} \mathrm{~g}^{-1}$ and $0.021 \mu \mathrm{mol} \mathrm{h} \mathrm{h}^{-1} \mathrm{~g}^{-1}$, respectively, in contrast to $\mathrm{Ti}_{3} \mathrm{C}_{2}$, wherein the production of $\mathrm{CO}$ and $\mathrm{CH}_{4}$ is $5.19 \mu \mathrm{mol} \mathrm{h}{ }^{-1} \mathrm{~g}^{-1}$, $0.044 \mu \mathrm{mol} \mathrm{h} \mathrm{h}^{-1} \mathrm{~g}^{-1}$, respectively. The isotopic experiments confirm that the product is produced by the photocatalytic reduction of $\mathrm{CO}_{2}$.

The tests of PL and TRPL showed that the composite rate of electron holes ${ }^{45,89}$ decreased significantly after carrying $\mathrm{Ti}_{3} \mathrm{C}_{2}$. As shown in Fig. 18(b), the fitted pure phase $\mathrm{C}_{3} \mathrm{~N}_{4}$ had a lifetime of only $4.14 \mathrm{~ns}$, while $10 \mathrm{TC}$ had a lifetime of $4.51 \mathrm{~ns}$, which represents a significant increase in the lifetime of the carriers. This is closely related to the smooth carrying of $\mathrm{Ti}_{3} \mathrm{C}_{2}$. An excellent "storage capacitor" is produced when $\mathrm{Ti}_{3} \mathrm{C}_{2}$ forms a heterojunction with $\mathrm{g}-\mathrm{C}_{3} \mathrm{~N}_{4}$. When the electrons are transmitted to the semiconductor surface, they transfer to $\mathrm{Ti}_{3} \mathrm{C}_{2}$ quickly while the holes cannot. This greatly reduces the electron hole composite and improves the photocatalytic performance of the material. On the other hand, abundant defects on the $\mathrm{Ti}_{3} \mathrm{C}_{2}$ surface provide excellent sites for $\mathrm{CO}_{2}$ adsorption.

In conclusion, the application of $\mathrm{Ti}_{3} \mathrm{C}_{2} \mathrm{~T}_{x}$ in $\mathrm{CO}_{2} \mathrm{RR}$ is relatively less than that of photocatalytic water splitting. This is because of its instability and its own carbon resources, which can cause interferences during the photocatalytic $\mathrm{CO}_{2}$ reduction reaction. As shown in Table 2, among limited reports, $\mathrm{Ti}_{3} \mathrm{C}_{2} \mathrm{~T}_{x}$ with both single-layered structures and multi-layered structures shows an obvious production promotion. It is to be noted that there are no new products (such as $\mathrm{C}_{2}$ products, formaldehyde, and methyl ether) after loading with $\mathrm{Ti}_{3} \mathrm{C}_{2} \mathrm{~T}_{x}$ compared to the base photocatalyst. This phenomenon confirms that $\mathrm{Ti}_{3} \mathrm{C}_{2} \mathrm{~T}_{x}$ cannot change the energy barrier of the base photocatalyst for $\mathrm{CO}_{2}$ reduction. Thus, in general, the obvious promotion during $\mathrm{CO}_{2} \mathrm{RR}$ may be related to the two features of $\mathrm{Ti}_{3} \mathrm{C}_{2} \mathrm{~T}_{x}$ : (a) abundant surface vacancies for $\mathrm{CO}_{2}$ adsorption and (b) promoting the separation of carriers.

\subsection{Applications in degradation}

The main principle of photocatalytic degradation by photocatalytic semiconductor materials is that light stimulates the generation of oxidizing holes. ${ }^{90-93}$ These can oxidize dissolved oxygen into efficient oxygen-active species such as superoxide radicals $\left({ }^{\bullet} \mathrm{O}_{2}{ }^{-}\right)$, singlet oxygen $\left({ }^{\bullet} \mathrm{O}\right)$, and hydroxyl radicals $\left({ }^{\bullet} \mathrm{OH}\right)$. These species can directly oxidize the substrate. ${ }^{94-96}$ $\mathrm{Ti}_{3} \mathrm{C}_{2}$ has a wealth of surface groups and active sites, which are conducive for the adsorption of substrates. Accordingly, $\mathrm{Ti}_{3} \mathrm{C}_{2}$ has been of particular interest as a photoactive degradation catalyst. A summary of the previous studies investigating the application of $\mathrm{Ti}_{3} \mathrm{C}_{2}$ in photocatalytic degradation reactions is shown in Table 3. 

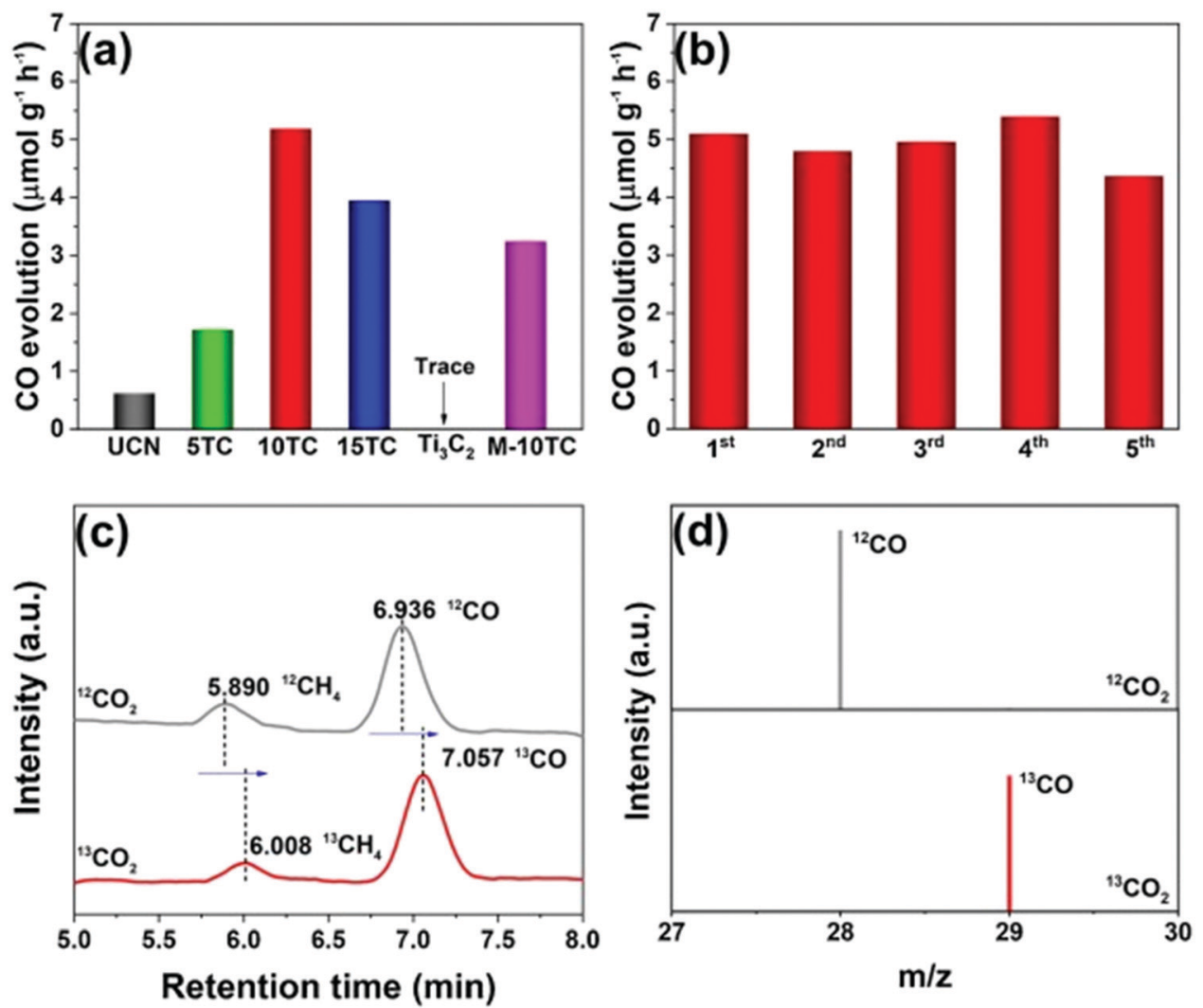

Fig. 17 Photocatalytic $\mathrm{CO}_{2}$ reduction performance of the as-prepared samples (a); cycling tests over the 10TC sample (b); GC-MS analysis of the products from the photoreduction of $\mathrm{CO}_{2}$ over $10 \mathrm{TC}$ using labelled ${ }^{12} \mathrm{CO}_{2}$ and ${ }^{13} \mathrm{CO}_{2}$ as the carbon sources (c and d) ${ }^{79}$

In 2018, Cai et al. produced a $\mathrm{Ag}_{3} \mathrm{PO}_{4} / \mathrm{Ti}_{3} \mathrm{C}_{2}$ composite photocatalyst, which possessed excellent photocatalytic degradation performance. ${ }^{87}$

As shown in Fig. 19, after DMSO and sonication treatment, $\mathrm{Ti}_{3} \mathrm{C}_{2}$ with a low-layer structure was formed. After the addition of silver nitrate, $\mathrm{Ag}^{+}$was adsorbed due to the negative charge on the surface of $\mathrm{Ti}_{3} \mathrm{C}_{2} . \mathrm{Ag}_{3} \mathrm{PO}_{4}$ nanoparticles were grown in situ, forming a heterojunction between the $\mathrm{Ag}_{3} \mathrm{PO}_{4}$ nanoparticles and the $\mathrm{Ti}_{3} \mathrm{C}_{2}$ nanosheets.

As shown in Fig. 20, the heterojunction of the $\mathrm{Ag}_{3} \mathrm{PO}_{4}$ nanoparticles/ $\mathrm{Ti}_{3} \mathrm{C}_{2}$ nanosheets shows a photocatalytic degradation stage rate $\mathrm{K}$ of $0.094,0.005,0.32$, and $0.0042 \mathrm{~min}^{-1}$ for methyl orange (MO), 2,4-dinitrophenol (2,4-DNP), tetracycline (TC-H), thiamphenicol (TPL), and chloramphenicol (CPL), respectively. According to EPR analysis, the hydroxyl radical $\left({ }^{\circ} \mathrm{OH}\right)$ plays an important role in the oxidation system, as shown in Fig. 20(f). This may be related to abundant Ti defects on the $\mathrm{Ti}_{3} \mathrm{C}_{2}$ surface. Ti sites exposed on the surface of $\mathrm{Ti}_{3} \mathrm{C}_{2}$ have strong redox reactivity, which promotes multiple electron reduction reactions $\left(\mathrm{O}_{2} \rightarrow \mathrm{H}_{2} \mathrm{O}_{2} \rightarrow{ }^{\bullet} \mathrm{OH}\right)$.

As shown in Fig. 21, PL, TRPL, and the electrochemical characterization spectra indicate that the carrier separation efficiency of the material is significantly improved after carrying $\mathrm{Ti}_{3} \mathrm{C}_{2}$. This may be attributed to (i) the abundant surface hydrophilic functional groups of the $\mathrm{Ti}_{3} \mathrm{C}_{2}$ construct, which have strong interfacial contact with $\mathrm{Ag}_{3} \mathrm{PO}_{4}$, facilitating the separation of carriers; (ii) the strong redox reactivity of the surface Ti sites, which promote multiple electron reduction reactions to induce more ${ }^{\bullet} \mathrm{OH}$ production; and (iii) a Schottky junction formed at the $\mathrm{Ag}_{3} \mathrm{PO}_{4} / \mathrm{Ti}_{3} \mathrm{C}_{2}$ interface enabling efficient transfer electrons to the $\mathrm{Ti}_{3} \mathrm{C}_{2}$ surface. This inhibits the photocossion of $\mathrm{Ag}_{3} \mathrm{PO}_{4}$ caused by photogeneration electrons.

Under high temperature conditions, $\mathrm{Ti}$ in the $\mathrm{Ti}_{3} \mathrm{C}_{2}$ skeleton layer is oxidized into $\mathrm{TiO}_{2}$, while $\mathrm{C}$ still exists in the form of a graphene-like layer. Therefore, under high temperature conditions, $\mathrm{Ti}_{3} \mathrm{C}_{2}$ can be converted into amorphous $\mathrm{TiO}_{2}$ anchored within the graphene-like layer. In 2020, Wu et al. took advantage of this material, which displayed excellent photocatalytic degradation performance. ${ }^{105}$

As shown in Fig. 22(e) and (f), high temperature treated $\mathrm{Ti}_{3} \mathrm{C}_{2}$ still retains its morphology and a $3 \mathrm{D}$ block-shaped morphology is formed after carrying g- $\mathrm{C}_{3} \mathrm{~N}_{4}$ (Fig. 23).

Graphene layers anchored to $\mathrm{TiO}_{2} / \mathrm{g}-\mathrm{C}_{3} \mathrm{~N}_{4}$ show first-order kinetic constants for the degradation of rhodamine $\mathrm{B}(\mathrm{RhB})$, tetracycline (TC), ciprofloxacin (CIP), and bisphenol A (BPA) of $0.0559,0.0244,0.0168$, and $0.0194 \mathrm{~min}^{-1}$, respectively. According to the EPR test results (Fig. 24(a)-(d)), the oxygen active species that play a role in the oxidation process mainly include ${ }^{\bullet} \mathrm{O}_{2}{ }^{-}$and ${ }^{\bullet} \mathrm{OH}$. Furthermore, signals corresponding to the holes $\left(\mathrm{h}^{+}\right)$were also detected. The contribution to the degradation of these test molecules appears to be in the order of ${ }^{\bullet} \mathrm{O}_{2}{ }^{-}>\mathrm{h}^{+}>$ $\bullet \mathrm{OH}$. 

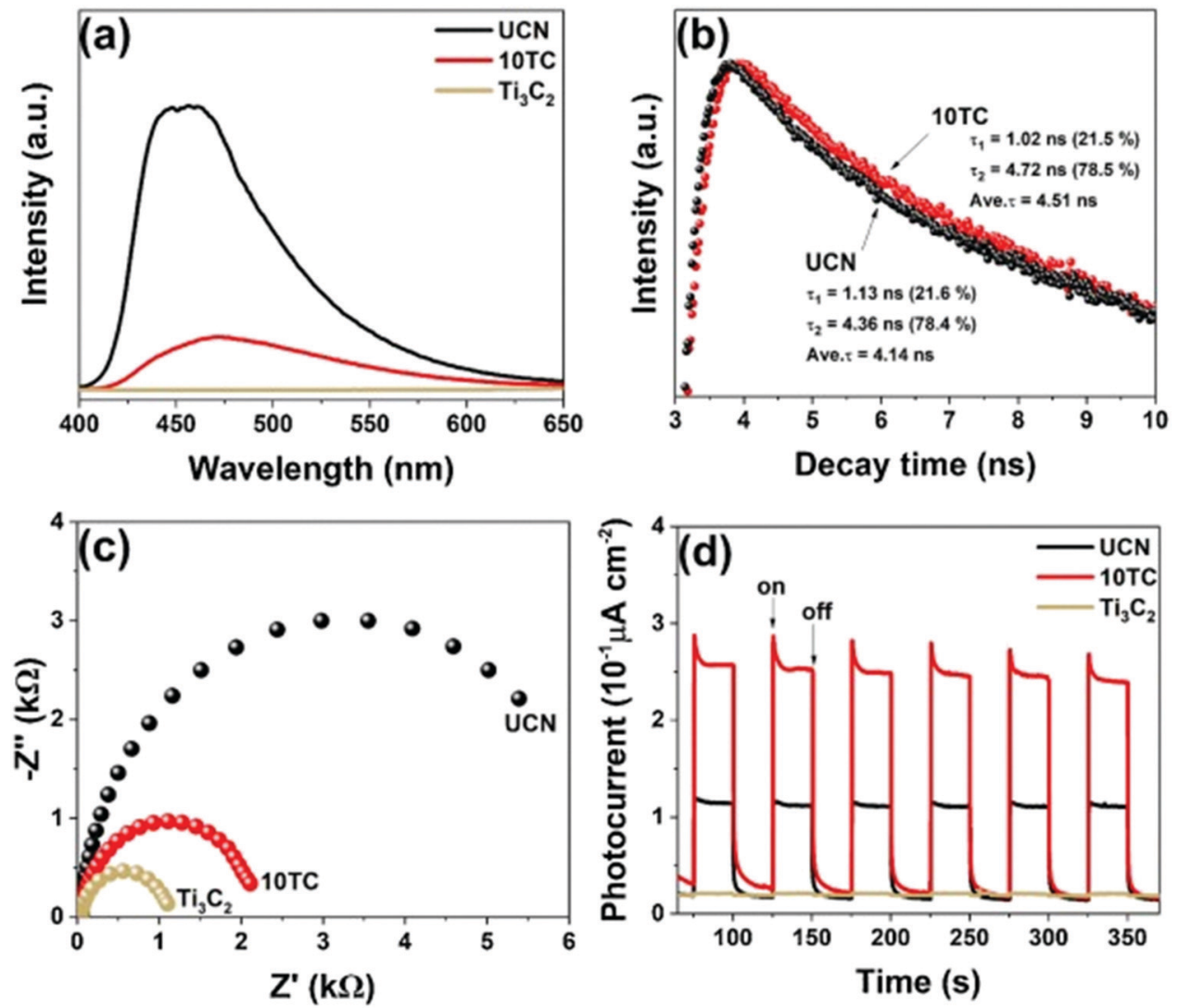

Fig. 18 PL spectra, EIS, and TPR plots of UCN, $\mathrm{Ti}_{3} \mathrm{C}_{2}$, and 10TC samples (a, C, and d); TR-PL spectra of UCN and 10TC (b). ${ }^{79}$

High-temperature treated $\mathrm{Ti}_{3} \mathrm{C}_{2}$ has a greatly enhanced light absorption capacity, whilst the carrier separation efficiency and transmission efficiency are also improved. The improvement of the photocurrent (Fig. 24(e) and (f)) also verified that the graphene layers anchoring $\mathrm{TiO}_{2}$ lead to the formation of a heterogeneous junction. This is due to the change in the electric field between $\mathrm{g}-\mathrm{C}_{3} \mathrm{~N}_{4}$.

In conclusion, as a co-catalyst, the application of $\mathrm{Ti}_{3} \mathrm{C}_{2} \mathrm{~T}_{x}$ in photocatalytic degradation is mainly due to its three characteristics: (a) in a liquid-solid phase reaction, its hydrophilicity makes it easy for the adsorption or contact between the pollutants and photocatalysts; (b) high throughput electron transfer makes it easier to generate concentrated holes $\left(\mathrm{h}^{+}\right)$; and (c) Ti sites exposed on the surface of $\mathrm{Ti}_{3} \mathrm{C}_{2}$ have strong redox reactivity, which promotes multiple electron reduction reactions, such as the reaction of activating molecular oxygen $\left(\mathrm{O}_{2} \rightarrow \mathrm{H}_{2} \mathrm{O}_{2} \rightarrow^{\bullet} \mathrm{OH}\right)$.

\section{Challenges}

The application of $\mathrm{Ti}_{3} \mathrm{C}_{2} \mathrm{~T}_{x}$ in photocatalysis is worthy of further investigation, despite the many problems that need to be solved. The main issue lies in the instability of the composite material, resulting in unstable photocatalytic performance. This contributes to the difficulty in determining the photocatalytic process mechanisms of $\mathrm{Ti}_{3} \mathrm{C}_{2} \mathrm{~T}_{x}$-based photocatalysts. Many of the existing solutions use either few- or single-layer structured materials. However, the preparation process of these is complex. Despite this, $\mathrm{Ti}_{3} \mathrm{C}_{2} \mathrm{~T}_{x}$ has an excellent optical response ability and displays broad catalytic activity.

\section{Summary and outlook}

\subsection{Summary}

In recent years, $\mathrm{Ti}_{3} \mathrm{C}_{2} \mathrm{~T}_{x}$ has attracted wide interest as a photocatalytic material due to its rich surface space and surface defects, hydrophilic properties, large interlayer spacing, and excellent microwave absorbing properties. $\mathrm{Ti}_{3} \mathrm{C}_{2} \mathrm{~T}_{x}$-based photocatalysts are widely used in hydrogen evolution reactions (HER), $\mathrm{CO}_{2}$ reduction reactions $\left(\mathrm{CO}_{2} \mathrm{RR}\right)$, photocatalytic degradation reactions, and show excellent catalytic performance. The application of $\mathrm{Ti}_{3} \mathrm{C}_{2} \mathrm{~T}_{x}$ in photocatalysis still warrants further investigation.

The further application of $\mathrm{Ti}_{3} \mathrm{C}_{2} \mathrm{~T}_{x}$ in photocatalysis depends on the development of the material itself. Methods to improve the stability of the $\mathrm{Ti}_{3} \mathrm{C}_{2} \mathrm{~T}_{x}$ structure need to be explored, starting from synthetic methods. In addition, the rich groups on the surface of $\mathrm{Ti}_{3} \mathrm{C}_{2} \mathrm{~T}_{x}$ and its hydrophilicity should be further explored, particularly in photocatalytic liquid phase reactions.

\subsection{Outlook}

5.2.1 Mechanism. During the photocatalytic reaction, especially the reaction including liquid phase, the mechanism 


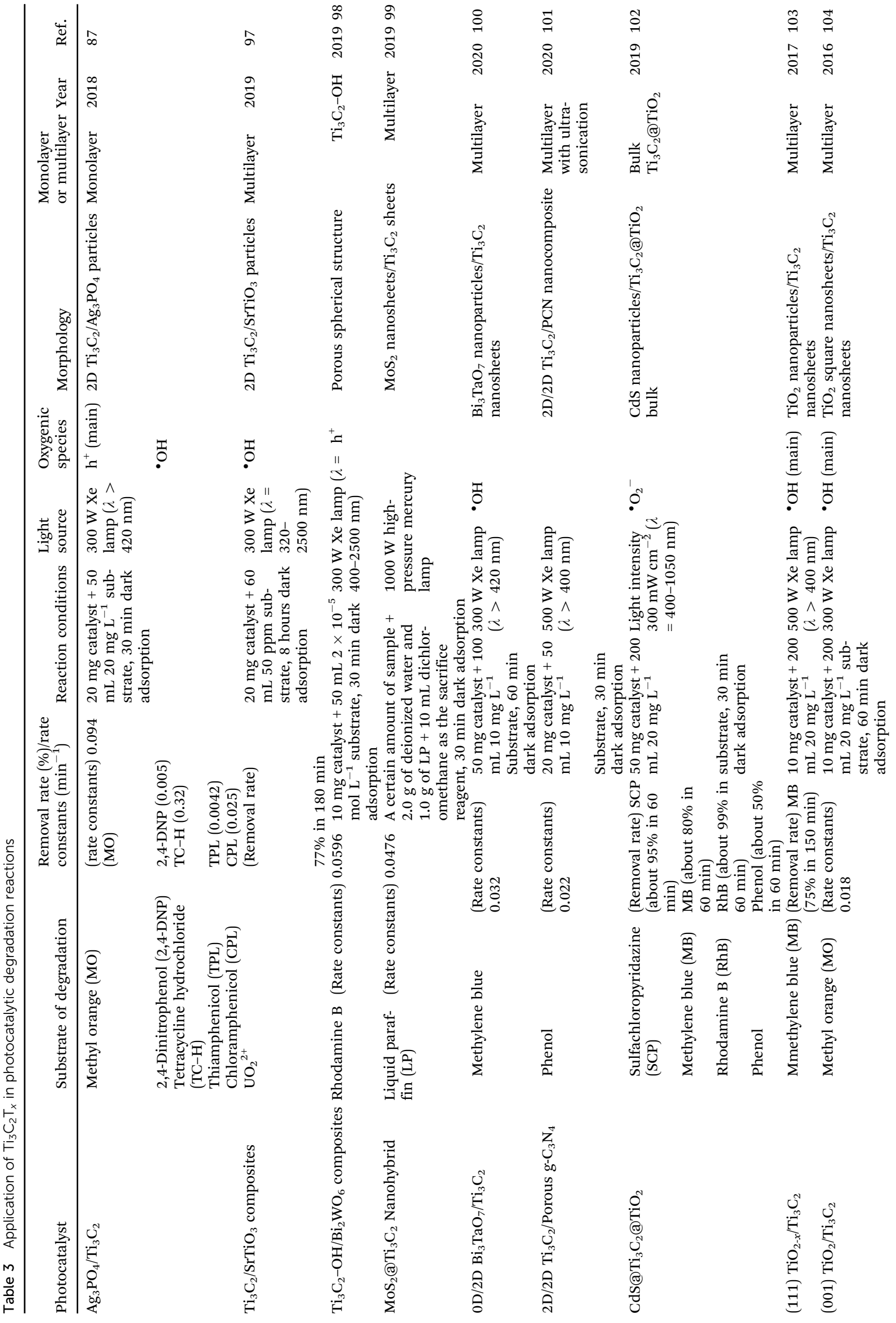




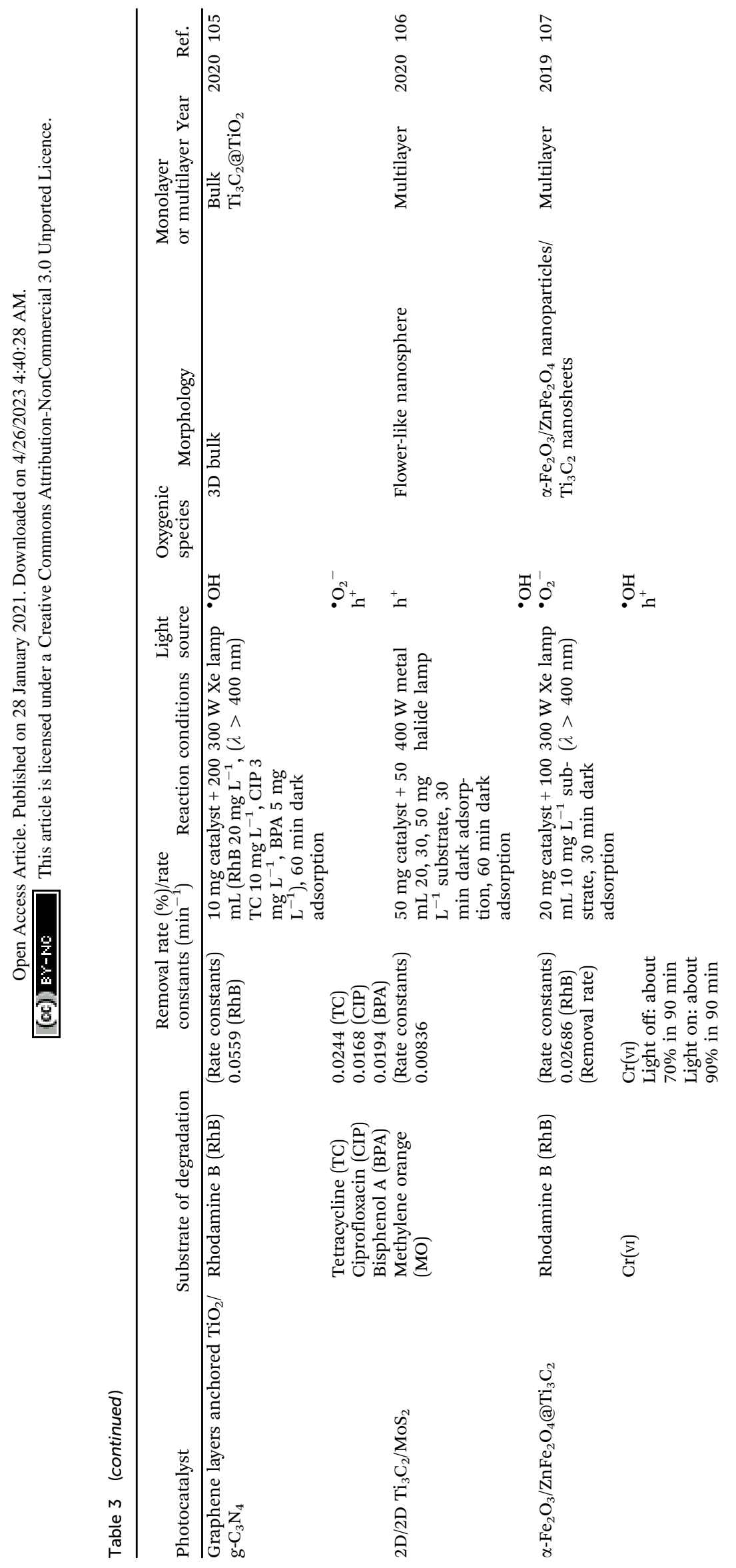


a

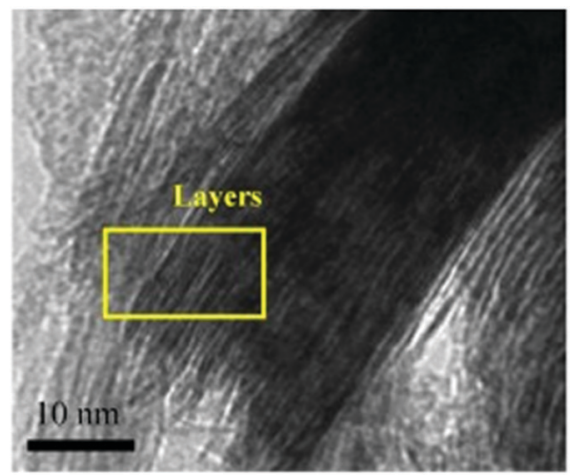

$\mathrm{c}$

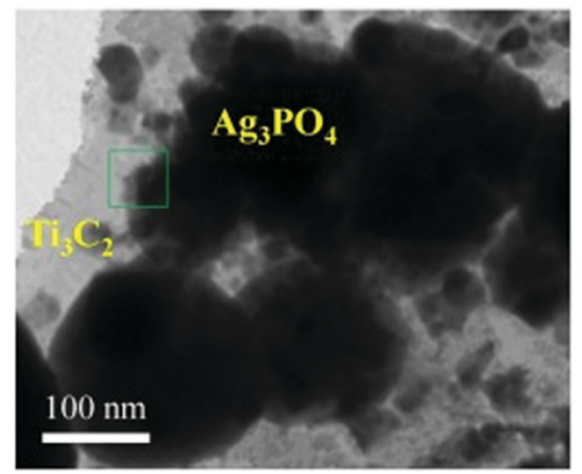

\section{e}
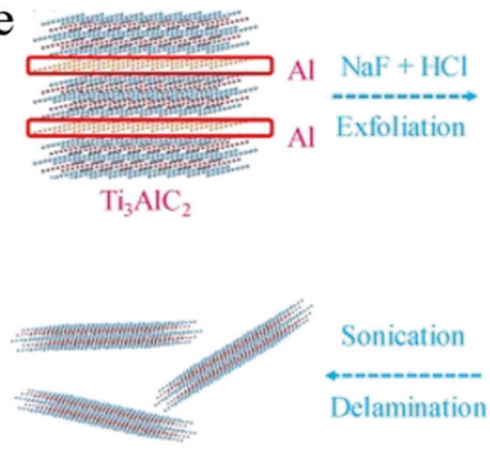

Delamination

Single $2 \mathrm{D} \mathrm{Ti}_{3} \mathrm{C}_{2}$

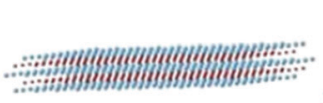

Single $2 \mathrm{D} \mathrm{Ti}_{3} \mathrm{C}_{2}$
Sonication

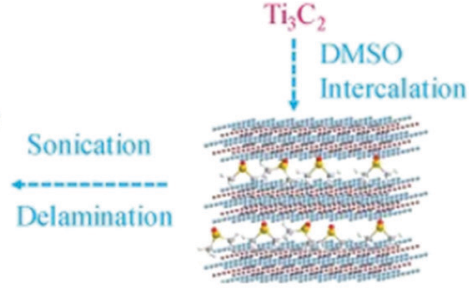

Intercalated $\mathrm{Ti}_{3} \mathrm{C}_{2}$
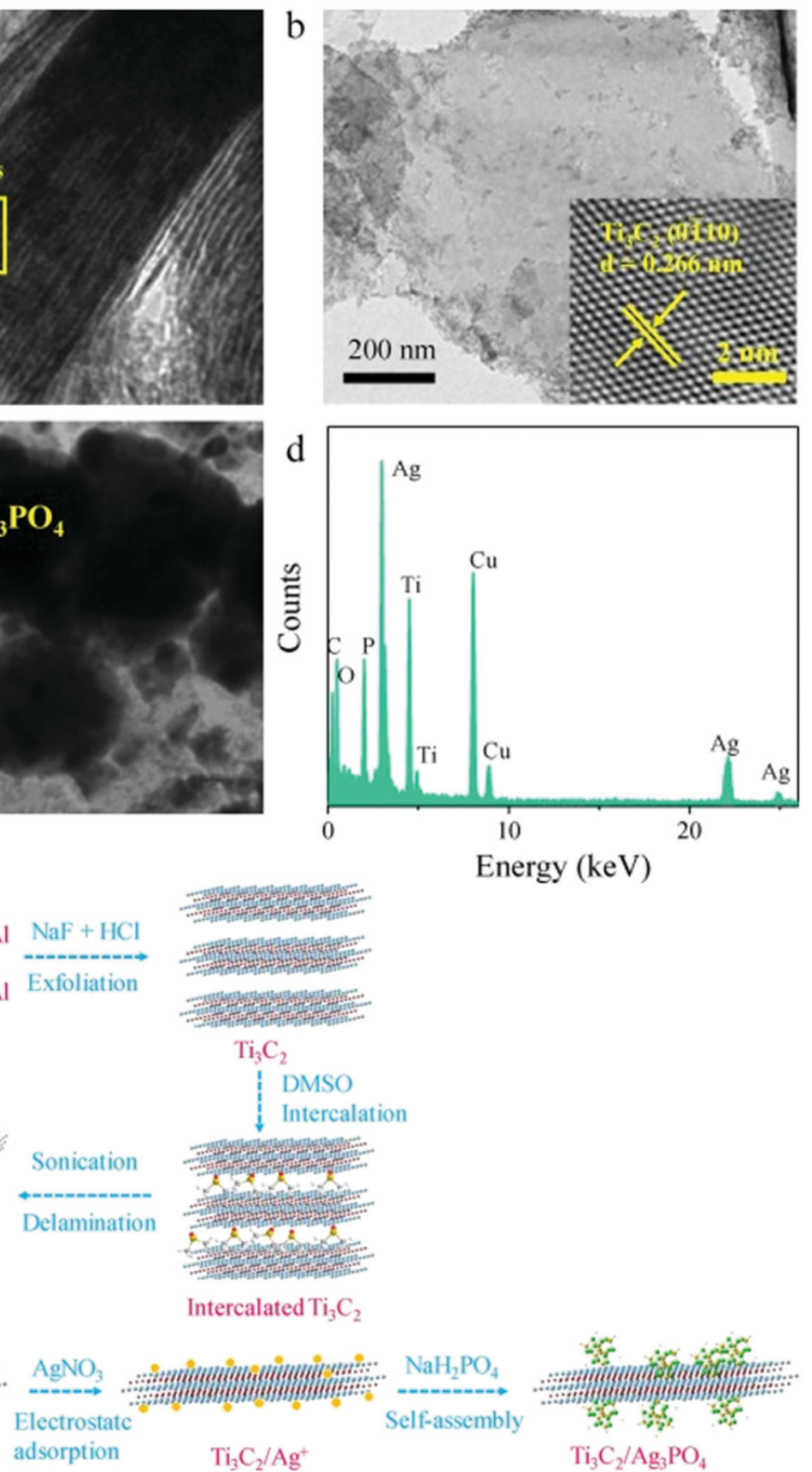

Fig. 19 TEM images of (a) bulk $\mathrm{Ti}_{3} \mathrm{C}_{2}$, (b) single $\mathrm{Ti}_{3} \mathrm{C}_{2}$ sheet, (c) $\mathrm{Ag}_{3} \mathrm{PO}_{4} / \mathrm{Ti}_{3} \mathrm{C}_{2}$ composite. (d) EDX spectra of the $\mathrm{Ag}_{3} \mathrm{PO}_{4} / \mathrm{Ti}_{3} \mathrm{C}_{2}$ composite and (e) the schematic representation of single $2 \mathrm{D} \mathrm{Ti}{ }_{3} \mathrm{C}_{2}$ sheets and $\mathrm{Ag}_{3} \mathrm{PO}_{4} / \mathrm{Ti}_{3} \mathrm{C}_{2}$ synthesis. ${ }^{87}$

needs to be explored. As is known to all, the structure of pure $\mathrm{Ti}_{3} \mathrm{C}_{2} \mathrm{~T}_{x}$ is not stable in both air and water. In air, the freshetched surface groups (such as $-\mathrm{OH}$ and $-\mathrm{F}$ ) can be replaced by oxygen termination after being exposed to air for a period of time; in water, $\mathrm{Ti}_{3} \mathrm{C}_{2} \mathrm{~T}_{x}$ can even be oxidized after being replaced for 21 days in room temperature. ${ }^{108}$ Thus, it needs to be explored more whether the structure of $\mathrm{Ti}_{3} \mathrm{C}_{2} \mathrm{~T}_{x}$ is changed during the photocatalytic reaction and if it does, how it changes.

During photocatalytic $\mathrm{CO}_{2} \mathrm{RR}$, although both monolayerstructured and multilayer-structured $\mathrm{Ti}_{3} \mathrm{C}_{2} \mathrm{~T}_{x}$ exhibit high performance, isotope detection shows that some carbon resources come from $\mathrm{CO}_{2}$ molecular; thus, there are still some ambiguities and other possibilities. For example, the valence state of "C" in $\mathrm{Ti}_{3} \mathrm{C}_{2} \mathrm{~T}_{x}$ is mostly "-4", which makes it possible for $\mathrm{CO}_{2}$ to react with $\mathrm{Ti}_{3} \mathrm{C}_{2} \mathrm{~T}_{x}$ in order to form the $\mathrm{CO}$ as product; this pathway involves redox reaction rather than catalysis.

This, in all, the mechanism needs to be explored more, both during the photocatalytic reaction and the oxidation of $\mathrm{Ti}_{3} \mathrm{C}_{2} \mathrm{~T}_{x}$ itself. 

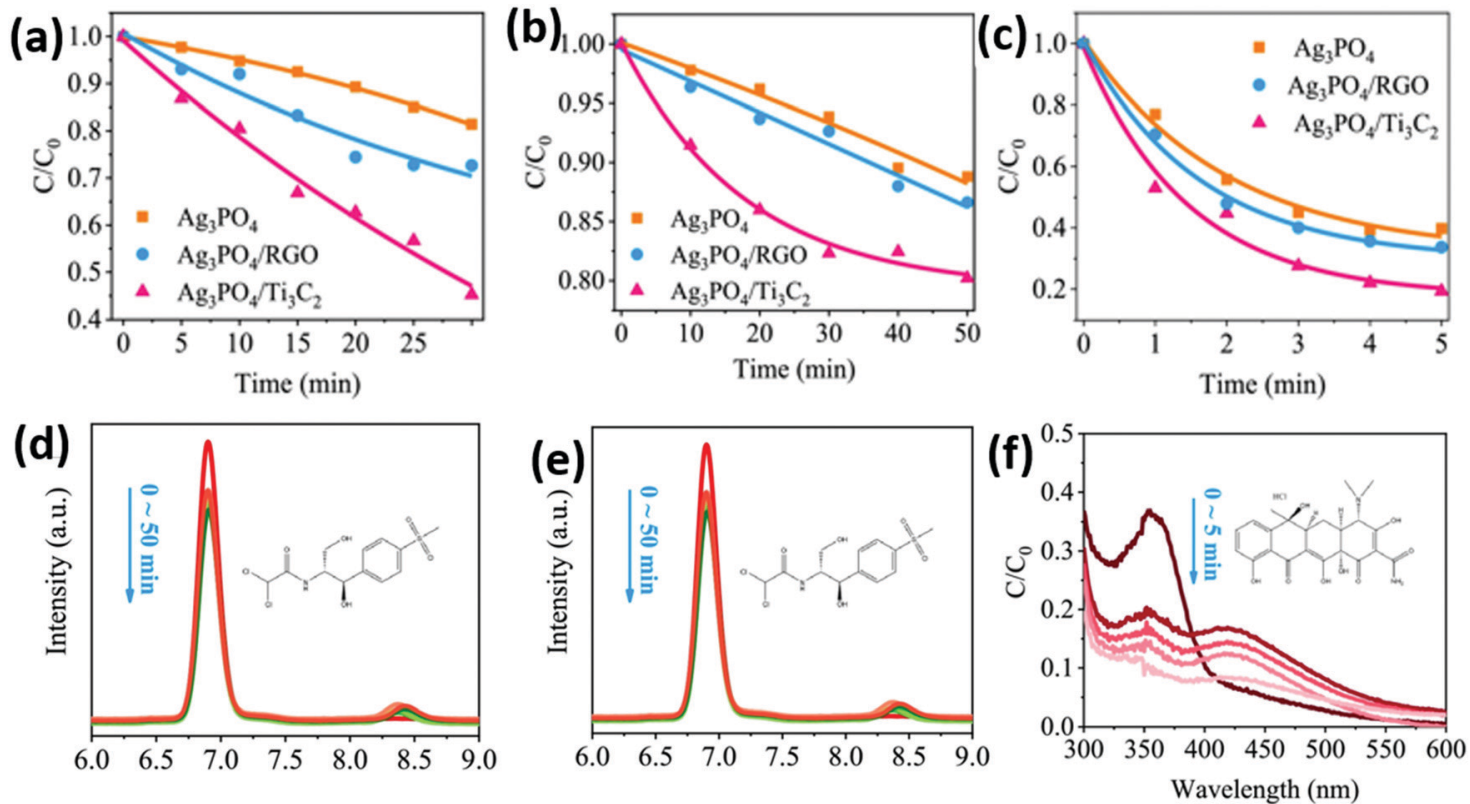

Fig. 20 Photocatalytic degradation of various pollutants by the as-prepared catalysts. (a) CPL, (b) TPL, and (c) TC-H degradation efficiency in the presence of the as-prepared catalysts under visible light irradiation ( $\lambda>420 \mathrm{~nm}$ ). HPLC chromatogram of (d) CPL and (e) TPL under different degradation times using the as-prepared catalysts. (f) UV-vis absorption spectra of $\mathrm{TC}-\mathrm{H}$ under different degradation times using different catalysts. ${ }^{87}$

(a)

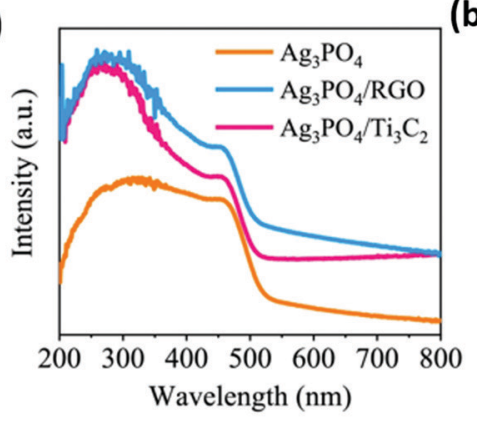

(d)

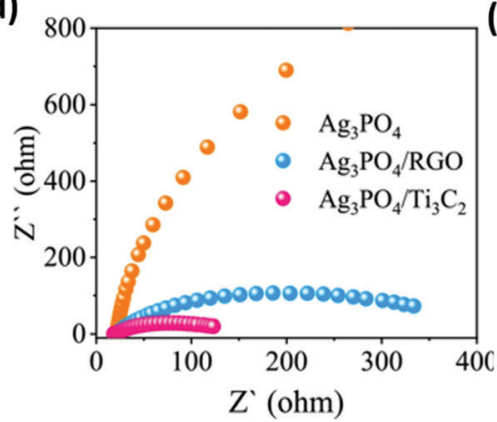

(b)

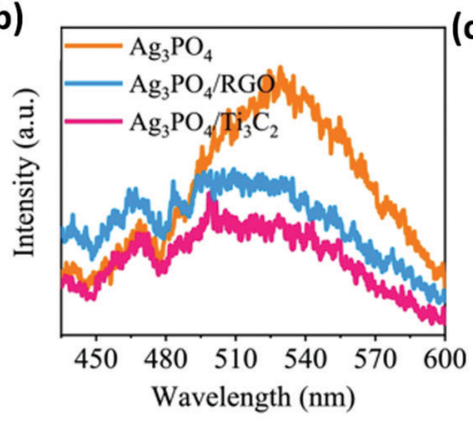

(e)

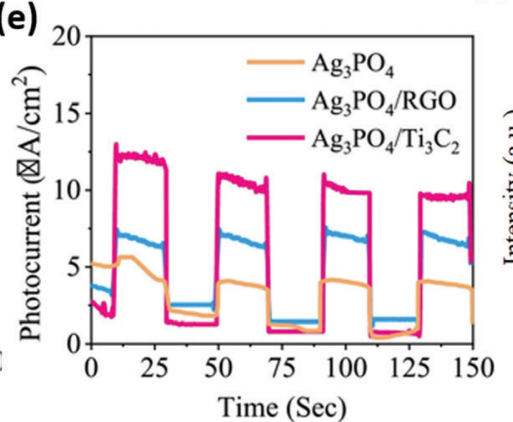

(c)

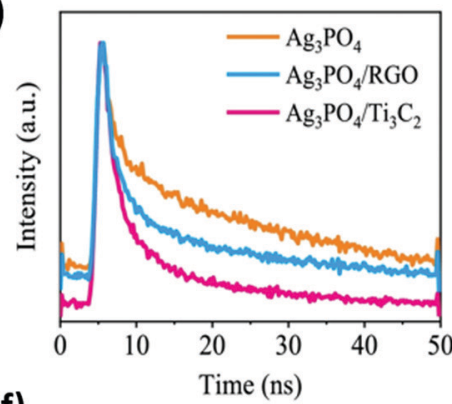

(f)

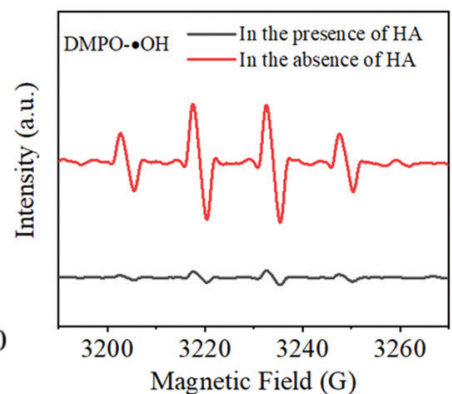

Fig. 21 UV-vis diffuse reflectance spectra (a), PL spectra (b), time-resolved PL decay spectra (c), EIS Nyquist plots (d), transient photocurrent responses (e) of the as-prepared catalysts, and DMPO spin-trapping ESR spectra for DMPO- $\bullet \mathrm{OH}_{\text {in }}$ the $\mathrm{Ag}_{3} \mathrm{PO}_{4} / \mathrm{Ti}_{3} \mathrm{C}_{2}$ system in the presence or absence of $\mathrm{HA}^{87}$

5.2.2 Development direction. The application of $\mathrm{Ti}_{3} \mathrm{C}_{2} \mathrm{~T}_{x}$ in photocatalysis is meaningful not just because it obviously promotes the reaction but also due to its applications in other new two-dimensional materials. For further applications, the following directions are necessary: to explore new methods of preparation to get structurally-stable $\mathrm{Ti}_{3} \mathrm{C}_{2} \mathrm{~T}_{x}$; to explore easier 

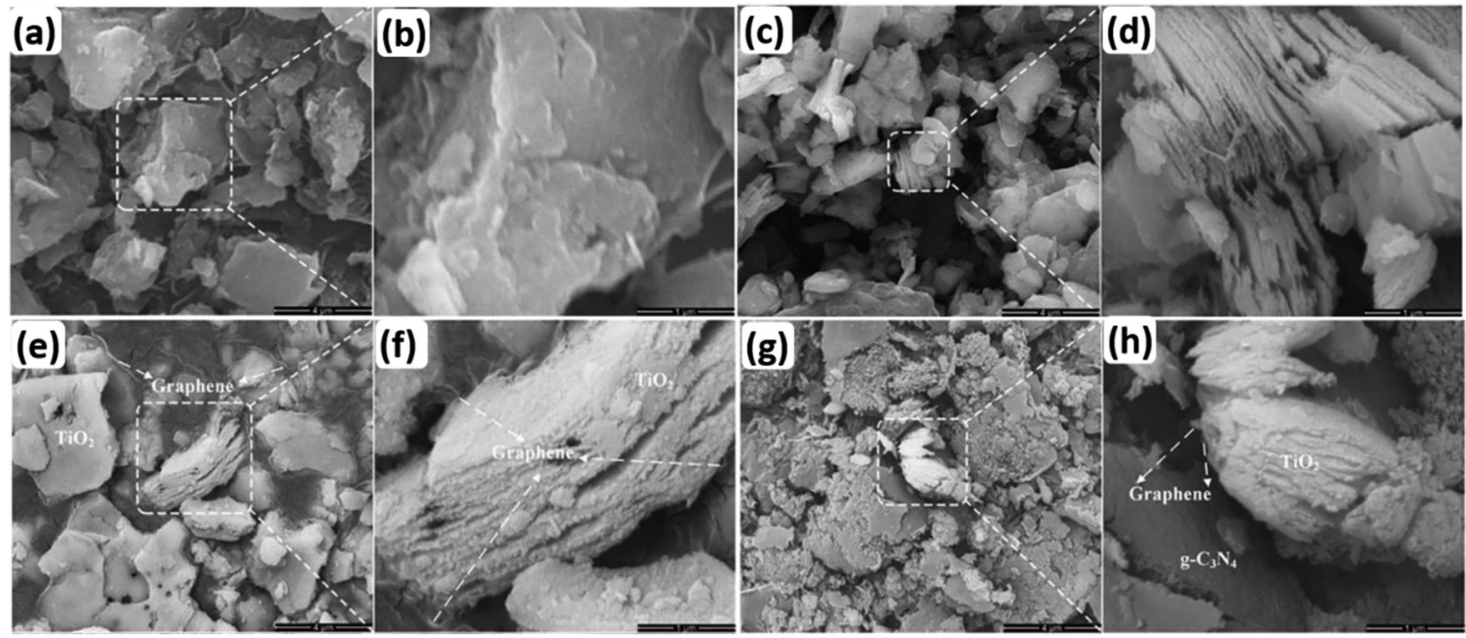

Fig. 22 SEM images of $\mathrm{C}_{3} \mathrm{~N}_{4}\left(\mathrm{a}\right.$ and b), $\mathrm{Ti}_{3} \mathrm{C}_{2}$ (c and d), heated $\mathrm{Ti}_{3} \mathrm{C}_{2}$ (e and f), and graphene layers anchored $\mathrm{TiO}_{2} / \mathrm{g}-\mathrm{C}_{3} \mathrm{~N}_{4}\left(\mathrm{~g}\right.$ and h). ${ }^{105}$
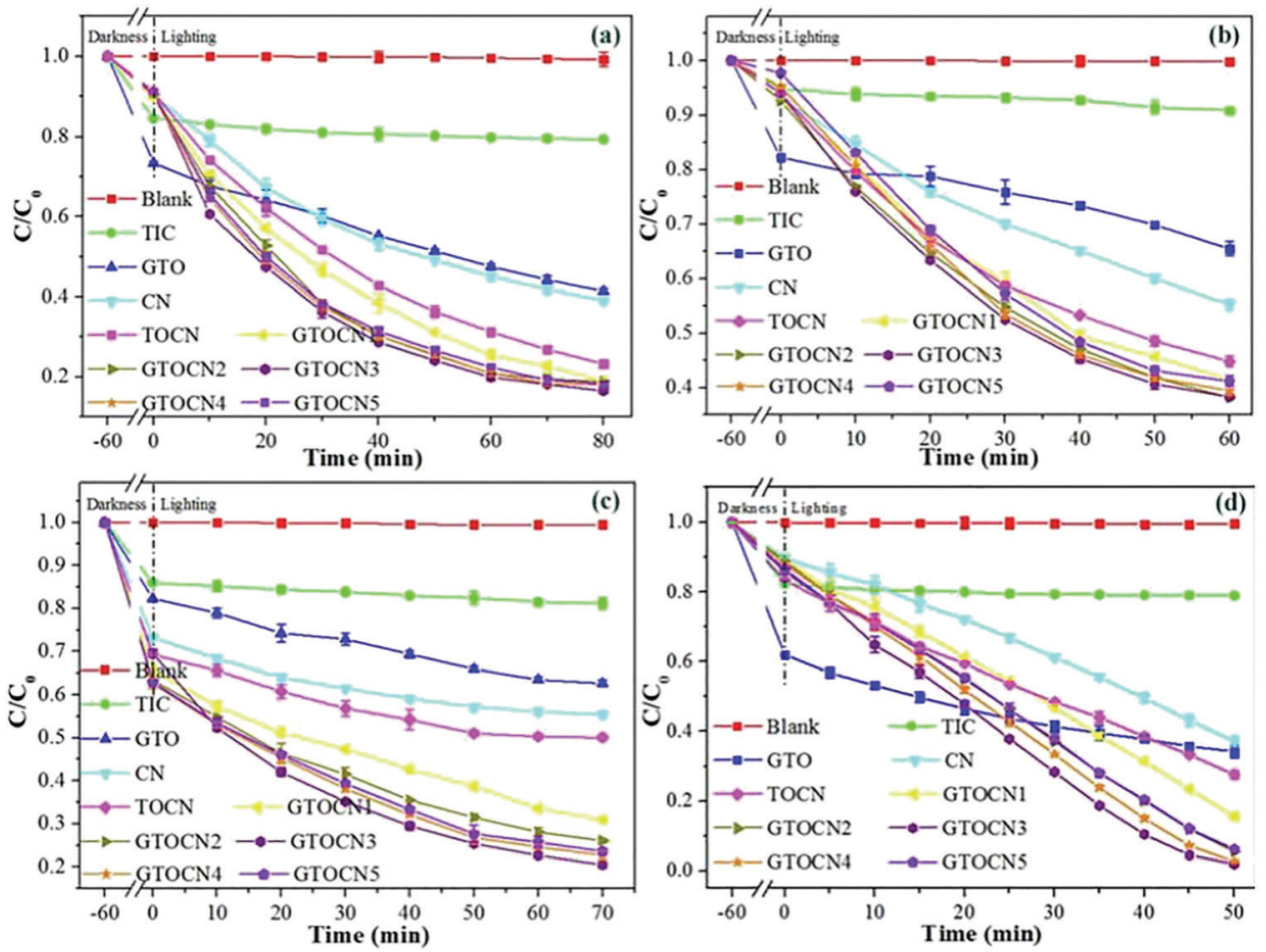

Fig. 23 The photocatalytic degradation performance of TC (a), CIP (b), BPA (c), and RhB (d) by photocatalysts under visible light irradiation. ${ }^{105}$

methods of preparation to get monolayered $\mathrm{Ti}_{3} \mathrm{C}_{2} \mathrm{~T}_{x}$; to explore more effective combination between $\mathrm{Ti}_{3} \mathrm{C}_{2} \mathrm{~T}_{x}$ and the base photocatalyst; to explore methods of regulating the surface groups and interlayer groups; to explore other application in the MXene family; to explore the mechanism.

$\mathrm{Ti}_{3} \mathrm{C}_{2} \mathrm{~T}_{x}$ is the earliest material in the MXene family; thus, the improvement of its application in photocatalysis represents a great significance for the application of the whole family.

\section{Conflicts of interest}

There are no conflicts to declare.

\section{Acknowledgements}

This work was supported by the National Natural Science Foundation of China (No. 51702270 and 51872147), the 111 Project (D20015), the Program for Innovative Research Team of 
(a)

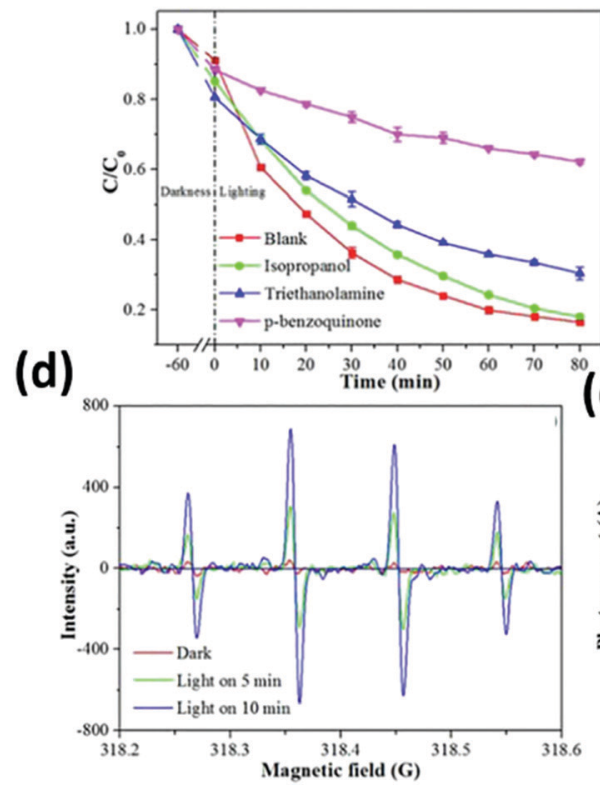

(b)

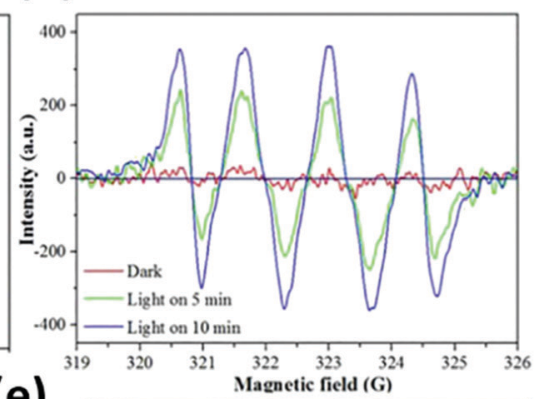

(c)

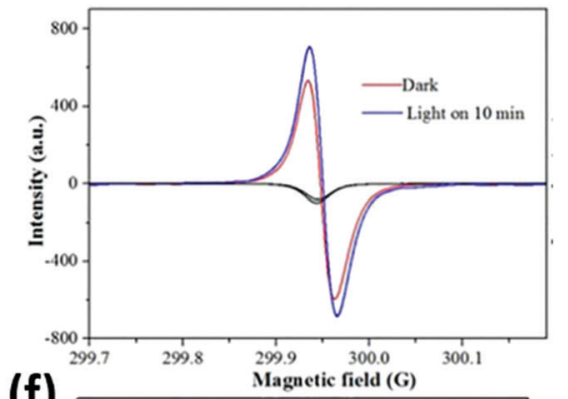

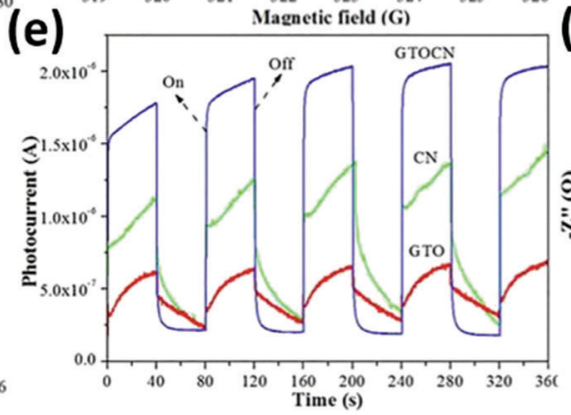

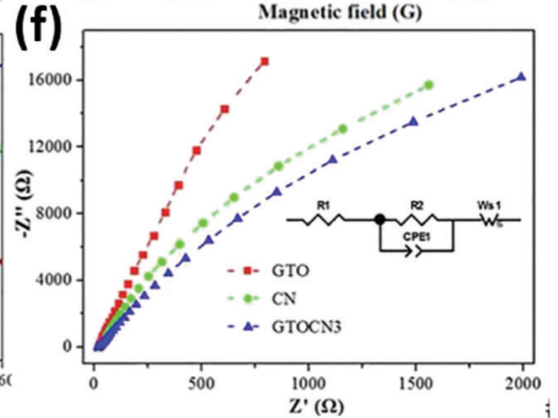

Fig. 24 Trapping experiment for the photocatalytic degradation of TC over GTOCN3 (a); ESR spectra of CNTOC3 for (b) DMPO-• ${ }_{2}^{-}$, (c) TEMPO- $\mathrm{h}^{+}$, (d) DMPO- $\cdot \mathrm{OH}$ in the dark and under visible light irradiation, $I-T$ curves under visible light irradiation (e) and the EIS response (f) of the samples. ${ }^{105}$

Science and Technology in the University of Henan Province (19IRTSTHN025), PetroChina Innovation Foundation (No. 2018D5007-0604), and Sichuan Science and Technology Program (No. 2020JDJQ0057).

\section{References}

1 J. Mao, Z. Liu and Z. Ren, Size effect in thermoelectric materials, npj Quantum Mater., 2016, 1(1), 16028.

2 X. Feng, G. Hu and J. Hu, Solution-phase synthesis of metal and/or semiconductor homojunction/heterojunction nanomaterials, Nanoscale, 2011, 3(5), 2099-2117.

3 S. Zhang, S. Guo, Z. Chen, Y. Wang, H. Gao, J. GomezHerrero, P. Ares, F. Zamora, Z. Zhu and H. Zeng, Recent progress in 2D group-VA semiconductors: from theory to experiment, Chem. Soc. Rev., 2018, 47(3), 982-1021.

4 M. Naguib, M. Kurtoglu, V. Presser, J. Lu, J. Niu, M. Heon, L. Hultman, Y. Gogotsi and M. W. Barsoum, Twodimensional nanocrystals produced by exfoliation of $\mathrm{Ti}_{3} \mathrm{AlC}_{2}$, Adv. Mater., 2011, 23(37), 4248-4253.

5 N. K. Chaudhari, H. Jin, B. Kim, D. San Baek, S. H. Joo and K. Lee, MXene: an emerging two-dimensional material for future energy conversion and storage applications, J. Mater. Chem. A, 2017, 5(47), 24564-24579.

6 Y. Zhang, L. Wang, N. Zhang and Z. Zhou, Adsorptive environmental applications of MXene nanomaterials: a review, RSC Adv., 2018, 8(36), 19895-19905.

7 K. Huang, Z. Li, J. Lin, G. Han and P. Huang, Twodimensional transition metal carbides and nitrides (MXenes) for biomedical applications, Chem. Soc. Rev., 2018, 47(14), 5109-5124.
8 B. Anasori, M. R. Lukatskaya and Y. Gogotsi, 2D metal carbides and nitrides (MXenes) for energy storage, Nat. Rev. Mater., 2017, 2(2), 16098.

9 T. Deng, J. Sun, P. Tai, Y. Wang, L. Zhang, H. Chang, Z. Wang, L. Niu, Y. Sheng, D. Xue, Q. Huang, Y. Zhou, P. Song and J. Li, $\mathrm{Ti}_{3} \mathrm{AlC}_{2}$, a candidate structural material for innovative nuclear energy system: the microstructure phase transformation and defect evolution induced by energetic heavy-ion irradiation, Acta Mater., 2020, 189, 188-203.

10 J. Halim, M. R. Lukatskaya, K. M. Cook, J. Lu, C. R. Smith, L. A. Naslund, S. J. May, L. Hultman, Y. Gogotsi, P. Eklund and M. W. Barsoum, Transparent conductive two-dimensional titanium carbide epitaxial thin films, Chem. Mater., 2014, 26(7), 2374-2381.

11 A. Hu, J. Yu, H. Zhao, H. Zhang and W. Li, One-step synthesis for cations intercalation of two-dimensional carbide crystal $\mathrm{Ti}_{3} \mathrm{C}_{2}$ MXene, Appl. Surf. Sci., 2020, 505, 144538.

12 M. Ghidiu, M. R. Lukatskaya, M. Q. Zhao, Y. Gogotsi and M. W. Barsoum, Conductive two-dimensional titanium carbide 'clay' with high volumetric capacitance, Nature, 2014, 516(7529), 78-81.

13 M. R. Lukatskaya, O. Mashtalir, C. E. Ren, Y. Dall'Agnese, P. Rozier, P. L. Taberna, M. Naguib, P. Simon, M. W. Barsoum and Y. Gogotsi, Cation intercalation and high volumetric capacitance of two-dimensional titanium carbide, Science, 2013, 341(6153), 1502-1505.

14 L. H. Karlsson, J. Birch, J. Halim, M. W. Barsoum and P. O. Persson, Atomically resolved structural and chemical investigation of single MXene sheets, Nano Lett., 2015, 15(8), 4955-4960. 
15 D. Magne, V. Mauchamp, S. Celerier, P. Chartier and T. Cabioc'h, Site-projected electronic structure of twodimensional $\mathrm{Ti}_{3} \mathrm{C}_{2}$ MXene: the role of the surface functionalization groups, Phys. Chem. Chem. Phys., 2016, 18(45), 30946-30953.

16 H. W. Wang, M. Naguib, K. Page, D. J. Wesolowski and Y. Gogotsi, Resolving the structure of $\mathrm{Ti}_{3} \mathrm{C}_{2} \mathrm{~T}_{x}$ MXenes through multilevel structural modeling of the atomic pair distribution function, Chem. Mater., 2016, 28(1), 349-359.

17 K. J. Harris, M. Bugnet, M. Naguib, M. W. Barsoum and G. R. Goward, Direct measurement of surface termination groups and their connectivity in the 2D MXene $\mathrm{V}_{2} \mathrm{CT}_{x}$ using NMR spectroscopy, J. Phys. Chem. C, 2015, 119(24), 13713-13720.

18 M. A. Hope, A. C. Forse, K. J. Griffith, M. R. Lukatskaya, M. Ghidiu, Y. Gogotsi and C. P. Grey, NMR reveals the surface functionalisation of $\mathrm{Ti}_{3} \mathrm{C}_{2}$ MXene, Phys. Chem. Chem. Phys., 2016, 18(7), 5099-5102.

19 Q. Xue, H. Zhang, M. Zhu, Z. Pei, H. Li, Z. Wang, Y. Huang, Y. Huang, Q. Deng, J. Zhou, S. Du, Q. Huang and C. Zhi, Photoluminescent $\mathrm{Ti}_{3} \mathrm{C}_{2}$ MXene quantum dots for multicolor cellular imaging, Adv. Mater., 2017, 29(15), 1604847.

20 D. Er, J. Li, M. Naguib, Y. Gogotsi and V. B. Shenoy, $\mathrm{Ti}_{3} \mathrm{C}_{2}$ MXene as a high capacity electrode material for metal ( $\mathrm{Li}$, $\mathrm{Na}, \mathrm{K}, \mathrm{Ca})$ ion batteries, ACS Appl. Mater. Interfaces, 2014, 6(14), 11173-11179.

21 Q. Tang, Z. Zhou and P. Shen, Are MXenes promising anode materials for $\mathrm{Li}$ ion batteries? Computational studies on electronic properties and Li storage capability of $\mathrm{Ti}_{3} \mathrm{C}_{2}$ and $\mathrm{Ti}_{3} \mathrm{C}_{2} \mathrm{X}_{2}(\mathrm{X}=\mathrm{F}, \mathrm{OH})$ monolayer, J. Am. Chem. Soc., 2012, 134(40), 16909-16916.

22 Q. Hu, D. Sun, Q. Wu, H. Wang, L. Wang, B. Liu, A. Zhou and J. He, MXene: a new family of promising hydrogen storage medium, J. Phys. Chem. A, 2013, 117(51), 14253-14260.

23 Y. Xie, Y. Dall'Agnese, M. Naguib, Y. Gogotsi, M. W. Barsoum, H. L. L. Zhuang and P. R. C. Kent, Prediction and characterization of MXene nanosheet anodes for non-lithium-ion batteries, ACS Nano, 2014, 8(9), 9606-9615.

24 C. Eames and M. S. Islam, Ion intercalation into twodimensional transition-metal carbides: global screening for new high-capacity battery materials, J. Am. Chem. Soc., 2014, 136(46), 16270-16276.

25 H. Pan, Ultra-high electrochemical catalytic activity of MXenes, Sci. Rep., 2016, 6, 32531.

26 M. Q. Zhao, C. E. Ren, Z. Ling, M. R. Lukatskaya, C. F. Zhang, K. L. Van Aken, M. W. Barsoum and Y. Gogotsi, Flexible MXene/Carbon nanotube composite paper with high volumetric capacitance, Adv. Mater., 2015, 27(2), 339-345.

27 Z. Guo, J. Zhou, L. Zhu and Z. Sun, MXene: a promising photocatalyst for water splitting, J. Mater. Chem. A, 2016, 4(29), 11446-11452.

28 M. Q. Zhao, C. E. Ren, Z. Ling, M. R. Lukatskaya, C. F. Zhang, K. L. Van Aken, M. W. Barsoum and Y. Gogotsi, Flexible MXene/Carbon nanotube composite paper with high volumetric capacitance, Adv. Mater., 2015, 27(2), 339-345.
29 G. Gao, A. P. O'Mullane and A. Du, 2D MXenes: A new family of promising catalysts for the hydrogen evolution reaction, ACS Catal., 2016, 7(1), 494-500.

30 J. Ran, G. Gao, F.-T. Li, T.-Y. Ma, A. Du and S.-Z. Qiao, $\mathrm{Ti}_{3} \mathrm{C}_{2}$ MXene co-catalyst on metal sulfide photo-absorbers for enhanced visible-light photocatalytic hydrogen production, Nat. Commun., 2017, 8(1), 13907.

31 M. Naguib, O. Mashtalir, M. R. Lukatskaya, B. Dyatkin, C. Zhang, V. Presser, Y. Gogotsi and M. W. Barsoum, Onestep synthesis of nanocrystalline transition metal oxides on thin sheets of disordered graphitic carbon by oxidation of MXenes, Chem. Commun., 2014, 50(56), 7420-7423.

32 X. Han, L. An, Y. Hu, Y. Li, C. Hou, H. Wang and Q. Zhang, $\mathrm{Ti}_{3} \mathrm{C}_{2}$ MXene-derived carbon-doped $\mathrm{TiO}_{2}$ coupled with g$\mathrm{C}_{3} \mathrm{~N}_{4}$ as the visible-light photocatalysts for photocatalytic $\mathrm{H}_{2}$ generation, Appl. Catal., B, 2020, 265, 118539.

33 X. Sang, Y. Xie, M. W. Lin, M. Alhabeb, K. L. Van Aken, Y. Gogotsi, P. R. C. Kent, K. Xiao and R. R. Unocic, Atomic defects in monolayer titanium carbide $\left(\mathrm{Ti}_{3} \mathrm{C}_{2} \mathrm{~T}_{x}\right)$ MXene, ACS Nano, 2016, 10(10), 9193-9200.

34 W. Zhou, X. Zou, S. Najmaei, Z. Liu, Y. Shi, J. Kong, J. Lou, P. M. Ajayan, B. I. Yakobson and J. C. Idrobo, Intrinsic structural defects in monolayer molybdenum disulfide, Nano Lett., 2013, 13(6), 2615-2622.

35 M. H. Gass, U. Bangert, A. L. Bleloch, P. Wang, R. R. Nair and A. K. Geim, Free-standing graphene at atomic resolution, Nat. Nanotechnol., 2008, 3(11), 676-681.

36 K. Takanabe, Photocatalytic Water Splitting: Quantitative Approaches toward Photocatalyst by Design, ACS Catal., 2017, 7(11), 8006-8022.

37 J. Ran, J. Zhang, J. Yu, M. Jaroniec and S. Z. Qiao, Earthabundant cocatalysts for semiconductor-based photocatalytic water splitting, Chem. Soc. Rev., 2014, 43(22), 7787-7812.

38 S. S. Chen, T. Takata and K. Domen, Particulate photocatalysts for overall water splitting, Nat. Rev. Mater., 2017, 2(10), 17050.

39 A. Kudo and Y. Miseki, Heterogeneous photocatalyst materials for water splitting, Chem. Soc. Rev., 2009, 38(1), 253-278.

40 Y. Jiao, Y. Zheng, M. Jaroniec and S. Z. Qiao, Design of electrocatalysts for oxygen- and hydrogen-involving energy conversion reactions, Chem. Soc. Rev., 2015, 44(8), 2060-2086.

41 J. K. Norskov, T. Bligaard, J. Rossmeisl and C. H. Christensen, Towards the computational design of solid catalysts, Nat. Chem., 2009, 1(1), 37-46.

42 J. K. Nørskov, T. Bligaard, A. Logadottir, J. R. Kitchin, J. G. Chen, S. Pandelov and U. Stimming, Trends in the exchange current for hydrogen evolution, J. Electrochem. Soc., 2005, 152(3), J23.

43 H. Berit, G. H. Poul, B. Jacob, P. J. Kristina, H. N. Jane, H. Sebastina, C. lb and K. N. Jens, Biomimetic hydrogen evolution: $\mathrm{MoS}_{2}$ nanoparticles as catalyst for hydrogen evolution, J. Am. Chem. Soc., 2005, 15(127), 5308-5309.

44 W. Yuan, L. Cheng, Y. Zhang, H. Wu, S. Lv, L. Chai, X. Guo and L. Zheng, 2D-layered Carbon/ $/ \mathrm{TiO}_{2}$ hybrids derived 
from $\mathrm{Ti}_{3} \mathrm{C}_{2}$ MXenes for photocatalytic hydrogen evolution under visible light irradiation, Adv. Mater. Interfaces, 2017, 4(20), 1700577.

45 H. Wang, R. Peng, Z. D. Hood, M. Naguib, S. P. Adhikari and $\mathrm{Z}$. Wu, Titania composites with $2 \mathrm{D}$ transition metal carbides as photocatalysts for hydrogen production under visible-light irradiation, ChemSusChem, 2016, 9(12), 1490-1497.

46 X. An, W. Wang, J. Wang, H. Duan, J. Shi and X. Yu, The synergetic effects of $\mathrm{Ti}_{3} \mathrm{C}_{2}$ MXene and Pt as co-catalysts for highly efficient photocatalytic hydrogen evolution over g- $\mathrm{C}_{3} \mathrm{~N}_{4}$. Phys. Chem.y, Chem. Phys., 2018, 20(16), 11405-11411.

47 W. Yuan, L. Cheng, Y. An, S. Lv, H. Wu, X. Fan, Y. Zhang, $\mathrm{X}$. Guo and J. Tang, Laminated hybrid junction of sulfurdoped $\mathrm{TiO}_{2}$ and a carbon substrate derived from $\mathrm{Ti}_{3} \mathrm{C}_{2}$ MXenes: toward highly visible light-driven photocatalytic hydrogen evolution, Adv. Sci., 2018, 5(6), 1700870.

48 Y. Li, X. Deng, J. Tian, Z. Liang and H. Cui, $\mathrm{Ti}_{3} \mathrm{C}_{2}$ MXenederived $\mathrm{Ti}_{3} \mathrm{C}_{2} / \mathrm{TiO}_{2}$ nanoflowers for noble-metal-free photocatalytic overall water splitting. Appl, Mater. Today, 2018, 13, 217-227.

49 H. Wang, Y. Sun, Y. Wu, W. Tu, S. Wu, X. Yuan, G. Zeng, Z. J. Xu, S. Li and J. W. Chew, Electrical promotion of spatially photoinduced charge separation via interfacialbuilt-in quasi-alloying effect in hierarchical $\mathrm{Zn}_{2} \mathrm{In}_{2} \mathrm{~S}_{5} /$ $\mathrm{Ti}_{3} \mathrm{C}_{2}(\mathrm{O}, \mathrm{OH})_{x}$ hybrids toward efficient photocatalytic hydrogen evolution and environmental remediation, Appl. Catal., B, 2019, 245, 290-301.

50 M. Zhang, J. Qin, S. Rajendran, X. Zhang and R. Liu, Heterostructured d- $\mathrm{Ti}_{3} \mathrm{C}_{2} / \mathrm{TiO}_{2} / \mathrm{g}-\mathrm{C}_{3} \mathrm{~N}_{4}$ nanocomposites with enhanced visible-light photocatalytic hydrogen production activity, ChemSusChem, 2018, 11(24), 4226-4236.

51 L. Tie, S. Yang, C. Yu, H. Chen, Y. Liu, S. Dong, J. Sun and J. Sun, In situ decoration of $\mathrm{ZnS}$ nanoparticles with $\mathrm{Ti}_{3} \mathrm{C}_{2}$ MXene nanosheets for efficient photocatalytic hydrogen evolution, J. Colloid Interface Sci., 2019, 545, 63-70.

52 R. Xiao, C. Zhao, Z. Zou, Z. Chen, L. Tian, H. Xu, H. Tang, Q. Liu, Z. Lin and X. Yang, In situ fabrication of 1D CdS nanorod/2D $\mathrm{Ti}_{3} \mathrm{C}_{2}$ MXene nanosheet Schottky heterojunction toward enhanced photocatalytic hydrogen evolution, Appl. Catal., B, 2020, 268, 118382.

53 Y. Zhuang, Y. Liu and X. Meng, Fabrication of $\mathrm{TiO}_{2}$ nanofibers/MXene $\mathrm{Ti}_{3} \mathrm{C}_{2}$ nanocomposites for photocatalytic $\mathrm{H}_{2}$ evolution by electrostatic self-assembly, Appl. Surf. Sci., 2019, 496, 143647.

54 T. Su, Z. D. Hood, M. Naguib, L. Bai, S. Luo, C. M. Rouleau, I. N. Ivanov, H. Ji, Z. Qin and Z. Wu, Monolayer $\mathrm{Ti}_{3} \mathrm{C}_{2} \mathrm{~T}_{x}$ as an effective co-catalyst for enhanced photocatalytic hydrogen production over $\mathrm{TiO}_{2}$, ACS Appl. Energy Mater., 2019, 2(7), 4640-4651.

$55 \mathrm{~J}$. Zhang, C. Xing and F. Shi, $\mathrm{MoS}_{2} / \mathrm{Ti}_{3} \mathrm{C}_{2}$ heterostructure for efficient visible-light photocatalytic hydrogen generation, Int. J. Hydrogen Energy, 2020, 45(11), 6291-6301.

56 P. Lin, J. Shen, X. Yu, Q. Liu, D. Li and H. Tang, Construction of $\mathrm{Ti}_{3} \mathrm{C}_{2}$ MXene/O-doped $\mathrm{g}-\mathrm{C}_{3} \mathrm{~N}_{4}$ 2D-2D Schottky- junction for enhanced photocatalytic hydrogen evolution, Ceram. Int., 2019, 45(18), 24656-24663.

57 L. Cheng, Q. Chen, J. Li and H. Liu, Boosting the photocatalytic activity of $\mathrm{CdLa}_{2} \mathrm{~S}_{4}$ for hydrogen production using $\mathrm{Ti}_{3} \mathrm{C}_{2}$ MXene as a co-catalyst, Appl. Catal., B, 2020, 267, 118379.

58 Y. Li, L. Ding, Y. Guo, Z. Liang, H. Cui and J. Tian, Boosting the photocatalytic ability of $\mathrm{g}-\mathrm{C}_{3} \mathrm{~N}_{4}$ for hydrogen production by $\mathrm{Ti}_{3} \mathrm{C}_{2}$ MXene quantum dots, ACS Appl. Mater. Interfaces, 2019, 11(44), 41440-41447.

59 Y. Li, L. Ding, Z. Liang, Y. Xue, H. Cui and J. Tian, Synergetic effect of defects rich $\mathrm{MoS}_{2}$ and $\mathrm{Ti}_{3} \mathrm{C}_{2}$ MXene as cocatalysts for enhanced photocatalytic $\mathrm{H}_{2}$ production activity of $\mathrm{TiO}_{2}$, Chem. Eng. J., 2020, 383, 123178.

60 P. Tian, X. He, L. Zhao, W. Li, W. Fang, H. Chen, F. Zhang, $\mathrm{Z}$. Huang and $\mathrm{H}$. Wang, $\mathrm{Ti}_{3} \mathrm{C}_{2}$ nanosheets modified Zr-MOFs with Schottky junction for boosting photocatalytic HER performance, Sol. Energy, 2019, 188, 750-759.

61 Z. Ai, K. Zhang, B. Chang, Y. Shao, L. Zhang, Y. Wu and $\mathrm{X}$. Hao, Construction of $\mathrm{CdS} @ \mathrm{Ti}_{3} \mathrm{C}_{2} @ \mathrm{CoO}$ hierarchical tandem $\mathrm{p}-\mathrm{n}$ heterojunction for boosting photocatalytic hydrogen production in pure water, Chem. Eng. J., 2020, 383, 123130.

62 J.-H. Zhao, L.-W. Liu, K. Li, T. Li and F.-T. Liu, Conductive $\mathrm{Ti}_{3} \mathrm{C}_{2}$ and MOF-derived $\operatorname{CoS}_{x}$ boosting the photocatalytic hydrogen production activity of $\mathrm{TiO}_{2}$, CrystEngComm, 2019, 21(14), 2416-2421.

63 Z. Ai, Y. Shao, B. Chang, B. Huang, Y. Wu and X. Hao, Effective orientation control of photogenerated carrier separation via rational design of a $\mathrm{Ti}_{3} \mathrm{C}_{2}\left(\mathrm{TiO}_{2}\right) @ \mathrm{CdS} / \mathrm{MoS}_{2}$ photocatalytic system, Appl. Catal., B, 2019, 242, 202-208.

64 Y. Li, Z. Yin, G. Ji, Z. Liang, Y. Xue, Y. Guo, J. Tian, X. Wang and $\mathrm{H}$. Cui, 2D/2D/2D heterojunction of $\mathrm{Ti}_{3} \mathrm{C}_{2}$ MXene/ $\mathrm{MoS}_{2}$ nanosheets/TiO ${ }_{2}$ nanosheets with exposed (001) facets toward enhanced photocatalytic hydrogen production activity, Appl. Catal., B, 2019, 246, 12-20.

65 J. Li, L. Zhao, S. Wang, J. Li, G. Wang and J. Wang, In situ fabrication of 2D/3D g- $\mathrm{C}_{3} \mathrm{~N}_{4} / \mathrm{Ti}_{3} \mathrm{C}_{2}$ (MXene) heterojunction for efficient visible-light photocatalytic hydrogen evolution, Appl. Surf. Sci., 2020, 515, 145922.

66 J. Zhang, M. Liu, Y. Wang and F. Shi, Au/MoS $/ \mathrm{Ti}_{3} \mathrm{C}_{2}$ composite catalyst for efficient photocatalytic hydrogen evolution, CrystEngComm, 2020, 22(21), 3683-3691.

67 T. Su, Z. D. Hood, M. Naguib, L. Bai, S. Luo, C. M. Rouleau, I. N. Ivanov, H. Ji, Z. Qin and Z. Wu, 2D/2D heterojunction of $\mathrm{Ti}_{3} \mathrm{C}_{2} / \mathrm{g}-\mathrm{C}_{3} \mathrm{~N}_{4}$ nanosheets for enhanced photocatalytic hydrogen evolution, Nanoscale, 2019, 11(17), 8138-8149.

68 J. Yin, F. Zhan, T. Jiao, W. Wang, G. Zhang, J. Jiao, G. Jiang, Q. Zhang, J. Gu and Q. Peng, Facile preparation of selfassembled MXene@Au@CdS nanocomposite with enhanced photocatalytic hydrogen production activity, Sci. China Mater., 2020, 63(11), 2228-2238.

69 Z. Yao, H. Sun, H. Sui and X. Liu, Construction of BPQDs/ $\mathrm{Ti}_{3} \mathrm{C}_{2} @ \mathrm{TiO}_{2}$ composites with favorable charge transfer channels for enhanced photocatalytic activity under visible light irradiation, Nanomater., 2020, 10(3), 452. 
70 J. Liu, H.-B. Zhang, R. Sun, Y. Liu, Z. Liu, A. Zhou and Z.-Z. Yu, Hydrophobic, flexible, and lightweight MXene foams for high-performance electromagnetic-interference shielding, Adv. Mater., 2017, 29(38), 1702367.

71 Y. Chen, G. Jia, Y. Hu, G. Fan, Y. H. Tsang, Z. Li and Z. Zou, Two-dimensional nanomaterials for photocatalytic $\mathrm{CO}_{2}$ reduction to solar fuels, Sustainable Energy Fuels, 2017, 1(9), 1875-1898.

72 J. Fu, K. Jiang, X. Qiu, J. Yu and M. Liu, Product selectivity of photocatalytic $\mathrm{CO}_{2}$ reduction reactions, Mater. Today, 2020, 32, 222-243.

73 K. Li, B. Peng and T. Peng, Recent advances in heterogeneous photocatalytic $\mathrm{CO}_{2}$ conversion to solar fuels, ACS Catal., 2016, 6(11), 7485-7527.

74 J. L. White, M. F. Baruch, J. E. Pander Iii, Y. Hu, I. C. Fortmeyer, J. E. Park, T. Zhang, K. Liao, J. Gu, Y. Yan, T. W. Shaw, E. Abelev and A. B. Bocarsly, Lightdriven heterogeneous reduction of carbon dioxide: photocatalysts and photoelectrodes, Chem. Rev., 2015, 115(23), 12888-12935.

75 X. Zhang, Z. Zhang, J. Li, X. Zhao, D. Wu and Z. Zhou, $\mathrm{Ti}_{2} \mathrm{CO}_{2}$ MXene: a highly active and selective photocatalyst for $\mathrm{CO}_{2}$ reduction, J. Mater. Chem. A, 2017, 5(25), 12899-12903.

76 H. He, P. Zapol and L. A. Curtiss, Computational screening of dopants for photocatalytic two-electron reduction of $\mathrm{CO}_{2}$ on anatase (101) surfaces, Energy Environ. Sci., 2012, 5(3), 6196-6205.

77 Y. Ji and Y. Luo, Theoretical study on the mechanism of photoreduction of $\mathrm{CO}_{2}$ to $\mathrm{CH}_{4}$ on the anatase $\mathrm{TiO}_{2}(101)$ surface, ACS Catal., 2016, 6(3), 2018-2025.

78 Y. Ji and Y. Luo, New mechanism for photocatalytic reduction of $\mathrm{CO}_{2}$ on the anatase $\mathrm{TiO}_{2}(101)$ surface: the essential role of oxygen vacancy, J. Am. Chem. Soc., 2016, 138(49), 15896-15902.

79 C. Yang, Q. Tan, Q. Li, J. Zhou, J. Fan, B. Li, J. Sun and K. Lv, 2D/2D Ti ${ }_{3} \mathrm{C}_{2}$ MXene/g- $\mathrm{C}_{3} \mathrm{~N}_{4}$ nanosheets heterojunction for high efficient $\mathrm{CO}_{2}$ reduction photocatalyst: Dual effects of urea, Appl. Catal., B, 2020, 268, 118738.

80 Q. Tang, Z. Sun, S. Deng, H. Wang and Z. Wu, Decorating g- $\mathrm{C}_{3} \mathrm{~N}_{4}$ with alkalinized $\mathrm{Ti}_{3} \mathrm{C}_{2}$ MXene for promoted photocatalytic $\mathrm{CO}_{2}$ reduction performance, J. Colloid Interface Sci., 2020, 564, 406-417.

81 J. Low, L. Zhang, T. Tong, B. Shen and J. Yu, TiO ${ }_{2} / \mathrm{MXene}$ $\mathrm{Ti}_{3} \mathrm{C}_{2}$ composite with excellent photocatalytic $\mathrm{CO}_{2}$ reduction activity, J. Catal., 2018, 361, 255-266.

82 S. Cao, B. Shen, T. Tong, J. Fu and J. Yu, 2D/2D heterojunction of ultrathin $\mathrm{MXene} / \mathrm{Bi}_{2} \mathrm{WO}_{6}$ nanosheets for improved photocatalytic $\mathrm{CO}_{2}$ reduction, Adv. Funct. Mater., 2018, 28(21), 1800136.

83 F. He, B. Zhu, B. Cheng, J. Yu, W. Ho and W. Macyk, 2D/ 2D/0D $\mathrm{TiO}_{2} / \mathrm{C}_{3} \mathrm{~N}_{4} / \mathrm{Ti}_{3} \mathrm{C}_{2}$ MXene composite S-scheme photocatalyst with enhanced $\mathrm{CO}_{2}$ reduction activity, Appl. Catal., B., 2020, 272, 119006.

84 J. Halim, K. M. Cook, M. Naguib, P. Eklund, Y. Gogotsi, J. Rosen and M. W. Barsoum, X-ray photoelectron spectroscopy of select multi-layered transition metal carbides (MXenes), Appl. Surf. Sci., 2016, 362, 406-417.

85 L. Liang, F. Lei, S. Gao, Y. Sun, X. Jiao, J. Wu, S. Qamar and Y. Xie, Single unit cell bismuth tungstate layers realizing robust solar $\mathrm{CO}_{2}$ reduction to methanol, Angew. Chem., Int. Ed., 2015, 54(47), 13971-13974.

86 H. Lin, X. Wang, L. Yu, Y. Chen and J. Shi, Twodimensional ultrathin MXene ceramic nanosheets for photothermal conversion, Nano Lett., 2017, 17(1), 384-391.

87 T. Cai, L. Wang, Y. Liu, S. Zhang, W. Dong, H. Chen, X. Yi, J. Yuan, X. Xia, C. Liu and S. Luo, $\mathrm{Ag}_{3} \mathrm{PO}_{4} / \mathrm{Ti}_{3} \mathrm{C}_{2}$ MXene interface materials as a Schottky catalyst with enhanced photocatalytic activities and anti-photocorrosion performance, Appl. Catal., B, 2018, 239, 545-554.

88 X. Zhao, M. Liu, Y. Chen, B. Hou, N. Zhang, B. Chen, N. Yang, K. Chen, J. Li and L. An, Fabrication of layered $\mathrm{Ti}_{3} \mathrm{C}_{2}$ with an accordion-like structure as a potential cathode material for high performance lithium-sulfur batteries, J. Mater. Chem. A, 2015, 3(15), 7870-7876.

89 J. Qian, A. Yuan, C. Yao, J. Liu, B. Li, F. Xi and X. Dong, Highly Efficient Photo-Reduction of p-nitrophenol by protonated graphitic carbon nitride nanosheets, ChemCatChem, 2018, 10(20), 4747-4754.

90 M. R. Hoffmann, S. T. Martin and W. Choi, Environmental Applications of semiconductor photocatalysis, Chem. Rev., 1995, 95(1), 69-96.

91 S. Dong, J. Feng, M. Fan, Y. Pi, L. Hu, X. Han, M. Liu, J. Sun and J. Sun, Recent developments in heterogeneous photocatalytic water treatment using visible light-responsive photocatalysts: a review, $R S C A d v$., 2015, 5(19), 14610-14630.

92 W. Guo, F. Zhang, C. Lin and Z. L. Wang, Direct growth of $\mathrm{TiO}_{2}$ nanosheet arrays on carbon fibers for highly efficient photocatalytic degradation of methyl orange, Adv. Mater., 2012, 24(35), 4761-4764.

$93 \mathrm{G}$. Xi and J. Ye, Synthesis of bismuth vanadate nanoplates with exposed $\{001\}$ facets and enhanced visible-light photocatalytic properties, Chem. Commun., 2010, 46(11), 1893-1895.

94 B. B. Adormaa, W. K. Darkwah and Y. Ao, Oxygen vacancies of the $\mathrm{TiO}_{2}$ nano-based composite photocatalysts in visible light responsive photocatalysis, RSC Adv., 2018, 8(58), 33551-33563.

95 V. Augugliaro, M. Bellardita, V. Loddo, G. Palmisano, L. Palmisano and S. Yurdakal, Overview on oxidation mechanisms of organic compounds by $\mathrm{TiO}_{2}$ in heterogeneous photocatalysis, J. Photochem. Photobiol., C, 2012, 13(3), 224-245.

96 Y. Nosaka and A. Y. Nosaka, Generation and Detection of Reactive Oxygen Species in Photocatalysis, Chem. Rev., 2017, 117(17), 11302-11336.

97 H. Deng, Z.-j. Li, L. Wang, L.-y. Yuan, J.-h. Lan, Z.-y. Chang, Z.-f. Chai, W.-q. Shi and Nanolayered $\mathrm{Ti}_{3} \mathrm{C}_{2}$, and $\mathrm{SrTiO}_{3}$ composites for photocatalytic reduction and removal of uranium(vi), ACS Appl. Nano Mater., 2019, 2(4), 2283-2294.

98 H. Fang, Y. Pan, M. Yin and C. Pan, Enhanced photocatalytic activity and mechanism of $\mathrm{Ti}_{3} \mathrm{C}_{2}-\mathrm{OH} / \mathrm{Bi}_{2} \mathrm{WO}_{6}: \mathrm{Yb}^{3+}, \mathrm{Tm}^{3+}$ 
towards degradation of RhB under visible and near infrared light irradiation, Mater. Res. Bull., 2020, 121, 110618.

99 S. Jiao and L. Liu, Friction-induced enhancements for photocatalytic degradation of $\mathrm{MoS}_{2} @ \mathrm{Ti}_{3} \mathrm{C}_{2}$ nanohybrid, Ind. Eng. Chem. Res., 2019, 58(39), 18141-18148.

100 K. Li, X. Lu, Y. Zhang, K. Liu, Y. Huang and H. Liu, $\mathrm{Bi}_{3} \mathrm{TaO}_{7} / \mathrm{Ti}_{3} \mathrm{C}_{2}$ heterojunctions for enhanced photocatalytic removal of water-borne contaminants, Environ. Res., 2020, 185, 109409.

101 N. Liu, N. Lu, H. Yu, S. Chen and X. Quan, Efficient day-night photocatalysis performance of $2 \mathrm{D} / 2 \mathrm{D} \mathrm{Ti}_{3} \mathrm{C}_{2} /$ Porous $\mathrm{g}-\mathrm{C}_{3} \mathrm{~N}_{4}$ nanolayers composite and its application in the degradation of organic pollutants, Chemosphere, 2020, 246, 125760.

102 Q. Liu, X. Tan, S. Wang, F. Ma, H. Znad, Z. Shen, L. Liu and $\mathrm{S}$. Liu, MXene as a non-metal charge mediator in $2 \mathrm{D}$ layered $\mathrm{CdS} @ \mathrm{Ti}_{3} \mathrm{C}_{2} @ \mathrm{TiO}_{2}$ composites with superior Z-scheme visible light-driven photocatalytic activity, Environ. Sci. Nano, 2019, 6(10), 3158-3169.

103 C. Peng, H. Wang, H. Yu and F. Peng, (111) TiO2 ${ }_{-x} /$ Ti3C2: Synergy of active facets, interfacial charge transfer and Ti3+ doping for enhance photocatalytic activity, Mater. Res. Bull., 2017, 89, 16-25.
104 C. Peng, X. Yang, Y. Li, H. Yu, H. Wang and F. Peng, Hybrids of two-dimensional $\mathrm{Ti}_{3} \mathrm{C}_{2}$ and $\mathrm{TiO}_{2}$ exposing $\{001\}$ facets toward enhanced photocatalytic activity, ACS Appl. Mater. Interfaces, 2016, 8(9), 6051-6060.

105 Z. Wu, Y. Liang, X. Yuan, D. Zou, J. Fang, L. Jiang, J. Zhang, $\mathrm{H}$. Yang and $\mathrm{Z}$. Xiao, MXene $\mathrm{Ti}_{3} \mathrm{C}_{2}$ derived Z-scheme photocatalyst of graphene layers anchored $\mathrm{TiO}_{2} / g-\mathrm{C}_{3} \mathrm{~N}_{4}$ for visible light photocatalytic degradation of refractory organic pollutants, Chem. Eng. J., 2020, 394, 124921.

106 Z. Yao, H. Sun, H. Sui and X. Liu, 2D/2D Heterojunction of R-scheme $\mathrm{Ti}_{3} \mathrm{C}_{2}$ MXene/MoS 2 nanosheets for enhanced photocatalytic performance, Nanoscale Res. Lett., 2020, 15(1), 78.

107 H. Zhang, M. Li, C. Zhu, Q. Tang, P. Kang and J. Cao, Preparation of magnetic $\alpha-\mathrm{Fe}_{2} \mathrm{O}_{3} / \mathrm{ZnFe}_{2} \mathrm{O}_{4} @ \mathrm{Ti}_{3} \mathrm{C}_{2}$ MXene with excellent photocatalytic performance, Ceram. Int., 2020, 46(1), 81-88.

108 X. Zhao, A. Vashisth, E. Prehn, W. Sun, S. A. Shah, T. Habib, Y. Chen, Z. Tan, J. L. Lutkenhaus, M. Radovic and M. J. Green, Antioxidants unlock shelf-stable $\mathrm{Ti}_{3} \mathrm{C}_{2} \mathrm{~T}$ (MXene) nanosheet dispersions, Matter, 2019, 1(2), 513-526. 